\title{
Different leaders: Emergent organizational and intellectual leadership in children's collaborative learning groups
}

\author{
Emma M. Mercier • Steven E. Higgins • Laura da Costa
}

Received: 28 February 2013 / Accepted: 9 July 2014 / Published online: 14 September 2014

(C) The Author(s) 2014. This article is published with open access at Springerlink.com

\begin{abstract}
This paper presents two studies that examine emergent leadership in children's collaborative learning groups. Building on research that finds that leadership moves are distributed among group members during learning activities, we examined whether there were patterns in the distribution of moves, resulting in different types of emergent leaders in groups. Study one examines individual groups working with a teacher, on the same task either with paper or multi-touch tables. Study two examines groups of students in a multi-touch classroom. Results from study one indicated that the leadership was distributed among the students; the distributions aligned with classifications of intellectual leadership moves and organizational leadership moves for about half of the groups. There were no differences in emergent leadership between the multi-touch and paper conditions. These results were explored in more detail in a multi-touch classroom study, exploring emergent leadership in 22 groups of students across six classes. Again, leadership was distributed among group members, and specific roles of intellectual and organizational leader, taken on by two different students, could be identified in half of the groups. These results suggest that attention should be paid to how students are engaging in collaborative learning tasks to ensure all students participate in the intellectual as well as organizational demands of the task. Additionally, the pattern of the distribution of roles suggests that care should be taken to specify behaviors if the role of leader is assigned to collaborative groups.
\end{abstract}

Keywords Emergent Roles · Leadership · Multi-touch Tables · Collaborative Learning · Interactive Surfaces $\cdot$ CSCL

\section{Introduction}

Georgia, Amy, Molly and Lucy ${ }^{1}$, four ten year old girls, stand around a multi-touch table, looking at the question "In which room is the statue hidden?" and 12 clues that contain number facts to determine the answer to the question (e.g., The room number is not even). As the

\footnotetext{
${ }^{1}$ All school and student names throughout the paper are pseudonyms.

E. M. Mercier $(\bowtie)$

University of Illinois at Urbana-Champaign, Champaign, IL, USA

e-mail: mercier@illinois.edu
}

S. E. Higgins $\cdot$ L. da Costa

Durham University, School of Education Leazes Road, Durham DH1 1TA, UK 
students begin moving the clues around the screen, Amy takes charge, monitoring participation and turn-taking, ensuring that each member of the group takes their turn to read a clue aloud, and then instructs the group which part of the screen to move the clues to, in order to keep track of their progress. Lucy, Georgia and Molly discuss the content of the clues, with Lucy and Georgia intervening at times to direct the conversation, summarizing and elaborating on the clues. The group finally decides the answer has to be either 35 or 45, having misunderstood the clue, "The number does not contain the digit three" as referring only to the unit 3 , not 3 as in 30 or 300 . The teacher directs them back to the clues, saying there is one they had missed, which they begin to look for:

Amy: "The statue is in a room whose number is lower than fifty", "The room number where it is hidden is a multiple of five", "The room number where the statue is hidden is not even." [reviewing 3 clues]

Lucy: So it could even be thirty, thirty-five, forty or forty-five.

Amy: No, thirty and forty are even aren't they? And it says that "the room number where the statue is hidden is not even"

Molly: So it's either thirty-five or forty-five [returning to the same conclusion as before]

Lucy: "The statue is hidden in a room in the grand hotel" [reading a clue]

Georgia: No, it's got to be forty-five.

Amy: How?

Georgia: Because of that one [points to clue] "It does not contain the digit three". Three, five, thirty-five.

Amy: Yeah, it's forty-five [agrees reluctantly]

This vignette, drawn from the first study in this paper, highlights the different roles that group members need to take in order to complete the collaborative task. Amy organizes the group, manages their participation and keeps them on track, while contributing to some of the idea development. Lucy and particularly Georgia push the ideas forward, managing the cognitive content and supporting their group members' understanding. The roles the three students play all have qualities of leadership, however, while Amy clearly organizes the task, she does not play as much of a role in the intellectual work, and appears somewhat confused by the final solution. Thus, while leadership is clearly distributed in this group, it appears to be systematically distributed, with particular aspects of the role taken by specific students, leading to different forms of engagement in the activity. In this paper, we explore the emergence of leadership in groups of students, looking at what leadership behaviors exist, and how they are distributed among participants.

Research on collaborative learning has recognized that attention needs to be paid to both the problem space and the relational space within which groups function in order to understand differential learning outcomes across groups (Barron 2003). However, to a large extent, earlier research focused on the problem space, the construction and development of ideas within groups, while issues around the relational space, and the management of participation in groups has received less attention (Miller et al. 2013). Managing participation has often been organized by instructors, either by assigning roles (e.g., Schellens et al. 2007), providing scripts (e.g., Weinberger et al. 2005), or assessment processes that reward individual participation, rather than allowing groups to manage their own participation (Johnson and Johnson 2009). However, as the field recognizes the importance of attending to group cognition (Stahl 2006; Volet et al. 2009), considers the processes of collaboration as important a learning experience as the learning that can be measured by individual outcomes, and thinks about how people become good collaborators (Barron et al. 2009), more focus has been placed on the emergent processes which group members use to manage participation. Three notable 
directions that this work has begun to take are emergent leadership, discussed below, analysis of uptake (Suthers 2006) and group regulation (Järvelä and Hadwin 2013).

Järvelä and Hadwin (2013) argue that successful management of participation within collaborative groups requires regulation at a number of levels: individuals' self-regulation, co-regulation between group members, and shared regulation at the group level. Here, goal directedness, metacognition, motivation, behaviors, and emotions are shared and coordinated in the creation, negotiation and navigation through the joint problem space (Roschelle, 1992). However, in contrast to entirely shared regulation, some leadership may still emerge within an effectively collaborating group, with one individual, for example, stimulating and sustaining collective motivations, while another leads and maintains active knowledge co-construction. In this way, some individuals' moves can be seen as bids for co-regulation or joint regulation. These bids seek to influence the interactions between group members and group level progress. Such regulation may be termed shared when those individuals' leadership moves are accepted and appropriated by the group at the individual and group level, while those individuals maintain initiative as leaders within the group.

These interactions have also been conceptualized as uptake (e.g., Suthers 2006), which is when a student engaged in a collaborative task "takes aspects of prior events as having relevance for ongoing activity" (Suthers et al. 2010, p 5). An uptake analysis framework aims to support the conceptualization, representation, and analysis of distributed and technologymediated interaction with 'uptake' as the basic unit of collaborative interaction. Understanding participation of collaborators, and the roles or actions that they take to maintain participation of all group members, requires consideration of the actions that students take both in terms of the interaction and problem space. While a desire for equal participation is frequently noted in the literature, this must be balanced with the need for groups to manage their participation and to change strategy or direction when necessary to reach their goal by introducing new ideas, which the leadership perspective offers.

In this paper, we expand on the few prior studies of emergent leadership (Gressick and Derry 2010; Li et al. 2007; Yamaguchi 2001), examining leadership through two studies of collaborative groups. However, while prior work has examined leadership as a single construct, but reports that it is often distributed within groups, we examine the distribution of moves that organize the group, and moves that drive the group forward intellectually, hypothesizing that these different types of leadership moves may not be made by the same group member. We consider the implications for groups, classrooms and the individual's learning depending on the leadership roles taken by specific students within a group and how the emergent distribution of leadership moves should be taken into account when assigning roles in groups.

Leadership is central to research on collaborative groups, taking a prominent place in management and organizational psychology literature in explaining the relative success or failure of groups (Avolio et al. 2009; Hackman 1990). Theories about leadership range from seeing it as a stable individual trait (e.g., Kirkpatrick and Locke 1991), a set of skills that can be acquired (e.g., Mumford et al. 2000) or a complex interaction between the individual, the context and the rest of the team (e.g., Seiler and Pfister 2009). More recently, the idea of leadership has been expanded to consider the ideas of distributed and joint leadership (e.g., Avolio et al. 2009; Li et al. 2007; Spillane 2005). This takes into account the range of behaviors that make up leadership, the reality that different aspects of leadership may be facilitated by different members of a team, and the importance of the interaction between leaders and followers in a team.

Emergent leadership in the management literature is defined as successful or unsuccessful attempts to undertake leadership moves when working in groups and has been criticized 
because most empirical studies focus on small groups rather than leadership across an organization (Bass and Bass 2009). The concept of distributed leadership across a group was conceptualized over sixty years ago (Gibb 1954; Bowers and Seashore 1966) with a number of reviews identifying various components, particularly from a management perspective (e.g., Bennett et al. 2003; Pearce and Conger 2003) and a clear recognition that there can be multiple leaders within a group taking different roles and responsibilities. There has been less focus on the relationship between distributed and emergent leadership within groups which Gronn (2002) has described as "conjoint agency," in which a few individuals emerge as leaders within a group and are able to synchronize their actions through reciprocal influence.

Prior research on emergent leadership in children's groups indicates the presence of emergent leadership, and its association with task completion and adult and peer nominations of leadership. Edwards (1994) reports on a 9-month long study of 4th-6th grade girls in Girl Scout Troops, finding that leadership was associated with organizational and goaloriented behaviors, and that emergent leadership, but not elected or assigned leadership, was consistent during the study.

French and Stright (1991) report on leadership in groups of second, fourth and sixth graders involved in a ranking task, focusing on how task facilitation behavior supports goal completion. Across two studies they found that leadership nominations were associated with task facilitation behaviors, solicitation of feedback and recording the group's activities. They also report strong associations between peer and teacher nominations of leadership and emergent leadership behavior.

The influence of task features on emergent leadership was explored by Yamaguchi (2001). In this study of ten groups of fourth to sixth graders, a distinction was made between dominant forms of leadership, which can be associated with bullying, and pro-social leadership. Results found that when the task had a performance goal, a dominant leader emerged, and in most cases, the task was not completed, while when there was a mastery goal for the task, leadership moves were distributed among group members. A later study by Yamaguchi and Maehr (2004) exploring self-reported measures of emergent leadership, group cohesion and group regulation, reports an association between these three measures. However, these self-reported measures were not associated with task completion, suggesting that there is more to be understood about emergent leadership than what members of a group perceive.

In an effort to identify leadership moves within groups, Li et al. (2007) developed a coding scheme to apply to twelve groups of fourth graders involved in a study designed to promote Collaborative Reasoning in the classroom. They identified five moves - turn management, argument development, planning and organizing, topic control and acknowledgement - as moves that leaders would make, and coded transcripts for evidence of these moves, using data drawn from 10 discussions in each group. Their results indicated that leadership was distributed within the groups, with only half of the groups showing a single clear leader, while another five showed evidence of shared leadership.

Building on the work of Li et al. (2007), Gressick and Derry (2010) report on a study of emergent leadership in online groups of future mathematics and science teachers. Adapting the coding scheme to suit the online nature of their data and the tasks, they again found that leadership was distributed among all members of the groups. However, they note that in some instances, the different leadership behaviors were differentially adopted by different members of a group, effectively sub-dividing the leadership role into smaller pieces. Certain moves, such as knowledge contribution, appear to be well distributed among the group members, while moves that structure the group or content, such as topic control or organizational moves were behaviors that were more frequently associated with a single member of the group. As with the Li et al. (2007) study, these results suggest that leadership within a learning group may 
be complex, distributed or shared among group members. Additionally, the data presented by Gressick and Derry suggest different forms of leadership emerging in groups, with some aspects of leadership behavior seen in one group member, while other aspects of leadership are enacted by another member of the group.

In this paper, we extend the work of Li et al. (2007) and Gressick and Derry (2010), adapting the same coding scheme to explore whether there is a pattern in the distribution of leadership moves among group members. In both studies, we begin by examining whether leadership moves are distributed among the group, and then examine whether particular students make more of each type of move.

In the Li et al. (2007) study, 12 groups of 4th grade students were followed over 10 sessions as they worked on Collaborative Reasoning tasks, and here changes were found over time, with more students taking on leadership roles with practice. Gressick and Derry (2010) examined groups of adult teacher education students working on the design of an instructional unit in an on-line context over six weeks, again finding some change over time. In this study, we examine a larger number of groups who worked on tasks in two different content areas, history and math, on a single day, to understand whether the patterns remained stable across content areas. Research on collaborative groups rarely looks at multiple content areas or task types within the same study, assuming to some degree, that collaborative behaviors are not related to task type or content. However, we wanted to explore whether the patterns of emergent leadership changed with different content areas (or task types), to extend our understanding about why roles might emerge within groups, and how they might be related to the particular collaborative activity or task.

\section{The present study}

In this paper, we present two studies of emergent leadership in children's collaborative learning groups. We define leadership moves as attempts to move the group forward, either by addressing issues of organization of the group, such as turn management, or addressing the intellectual aspects of the activity, such as idea management and development. However, as we view the group as the cognitive unit, leadership is not seen as the making of leadership moves, but as an interaction between members of a group, such that even though an individual is required to make a leadership bid for any leadership to emerge, the other members of the group must also react in acknowledgement of that move; leadership moves that are ignored by the group can be classified as failed bids for leadership. Thus leadership is defined as emerging when leadership bids are successful, and the participant who makes bids that are not taken up by the group cannot be defined as a leader.

Data for this paper is drawn from a large, four year study that focuses on using multi-touch technology to support collaborative learning in the classroom, and developing our understanding of how to support the processes of collaborative learning in formal learning environments. Multi-touch tables (see Fig. 1) allow multiple users to interact directly with a screen, creating the possibility of more equitable access in computer-supported collaborative learning activities. This technology has the potential to change the way co-located computer-supported collaborative learning activities can be designed, by removing the need for students to negotiate control of a single control device (e.g., a mouse or keyboard) (Dillenbourg and Evans 2011; Higgins et al. 2011). While research in this field is still relatively new, findings indicate that multi-touch tables can be supportive of the collaborative learning process when compared to more traditional materials. In research that compared groups of students working on the same task in a multi-touch and single-touch condition, Harris et al. (2009) reported higher levels of 


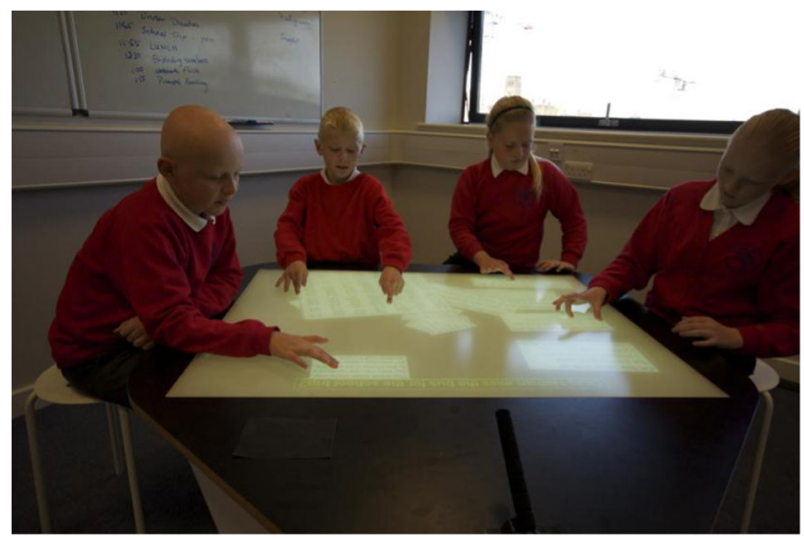

Fig. 1 Children working at a multi-touch table

task-focused conversation, and lower levels of process focused conversation in the multi-touch condition than in the single-touch condition, indicating that the use of multi-touch reduced the need to monitor participation and turn-taking, freeing groups to focus on the content.

In a study that compared undergraduate students working on a programming task in a multi-touch and a traditional personal computer (pc) condition, Basheri et al. (2013) reported that dyads spent more time in shared engagement in the task in the multi-touch condition and more time with one student working on the task while the other sat back from the task in the pc condition. Again, this work points toward the potential of the multi-touch table to support joint engagement on a task, and reduce the amount of time group members spend taking turns.

In a study drawing on the same data as is reported in study one in this paper, we found that groups working on a multi-touch table when completing a divergent historical reasoning task engaged in higher levels of interactive talk (elaborating and negotiating) than groups in the paper-based condition, whose statements were more limited to independent and quasiinteractive statements (Higgins et al. 2012). When comparing the groups working on math tasks across the two conditions, we found that although students raised similar numbers of ideas across conditions, students were more likely to respond to those ideas by elaborating or combining them with other ideas in the multi-touch condition than in the paper condition (Mercier et al. 2013). These findings point towards the potential of multi-touch tables to support more complex conversations between students working on a collaborative task.

Studies that examine the use of multi-touch tables in classroom environments indicate that the tables can be used for successful small group and whole class work. Mercier and Higgins (2013) report increased mathematical flexibility when students completed a collaborative expression-generating task in a multi-touch classroom, when compared to students completing an individual activity on paper. Additional research in this area indicates that the use of multiple networked tables can be used to provide data for teachers to understand more of what is happening in collaborative groups, and alter their interventions appropriately (Martinez-Maldonado et al. 2013; Mercier, et al. 2012). However, research on non-networked tables in classrooms reported the types of classroom and content management issues that are found in many non-technology supported collaborative activities (Kharrufa et al. 2013), indicating that more than just the tables are necessary for this technology to be used to effectively support collaborative learning in classrooms.

Study one is drawn from the initial study in this project, which sought to identify differences between groups using a multi-touch table and paper-based versions of the same 
tasks. As described elsewhere (Higgins et al. 2012; Mercier et al. 2013), each group worked with a teacher, who supported them in solving the math tasks, and coming to agreement on a solution for the history task. In this study we look at the emergent leadership in the groups and compare leadership across conditions. Due to the similarity in outcomes in all groups, the relationship between leadership and outcomes are not explored. In both conditions, video and audio was captured using two cameras (mounted on tri-pods in the paper-based condition, and ceiling-mounted in the multi-touch condition).

Study two is drawn from the next stage of the research project, where a classroom of multitouch tables was built explicitly to examine collaborative learning in a classroom setting (See Fig. 2). The classroom is set up to be similar to a standard classroom, where up to sixteen students work around four multi-touch tables. The classroom has a teacher desk, a podium multi-touch table from where the teacher can send content to the student tables, and project from the student tables to the interactive whiteboard to facilitate whole-class discussion. The classroom is equipped with recording equipment, which discreetly captures the interactions of the groups (through ceiling-mounted cameras and directional microphones embedded in the tables), the whole class processes (through ceiling-mounted fishbowl cameras) and table-use (through screen capture software).

In both study one and study two, two members of the research team, who had been primary (elementary) teachers, facilitated the lessons. In study one, one teacher worked with each group, although they aimed to allow the groups to work independently, intervening when the groups appeared to be stuck or asked directly for help or confirmation of their process. In the second study, each of the two teachers taught three of the classes, while the students' own teachers were watching a live stream of the classroom in another room. In both studies, group

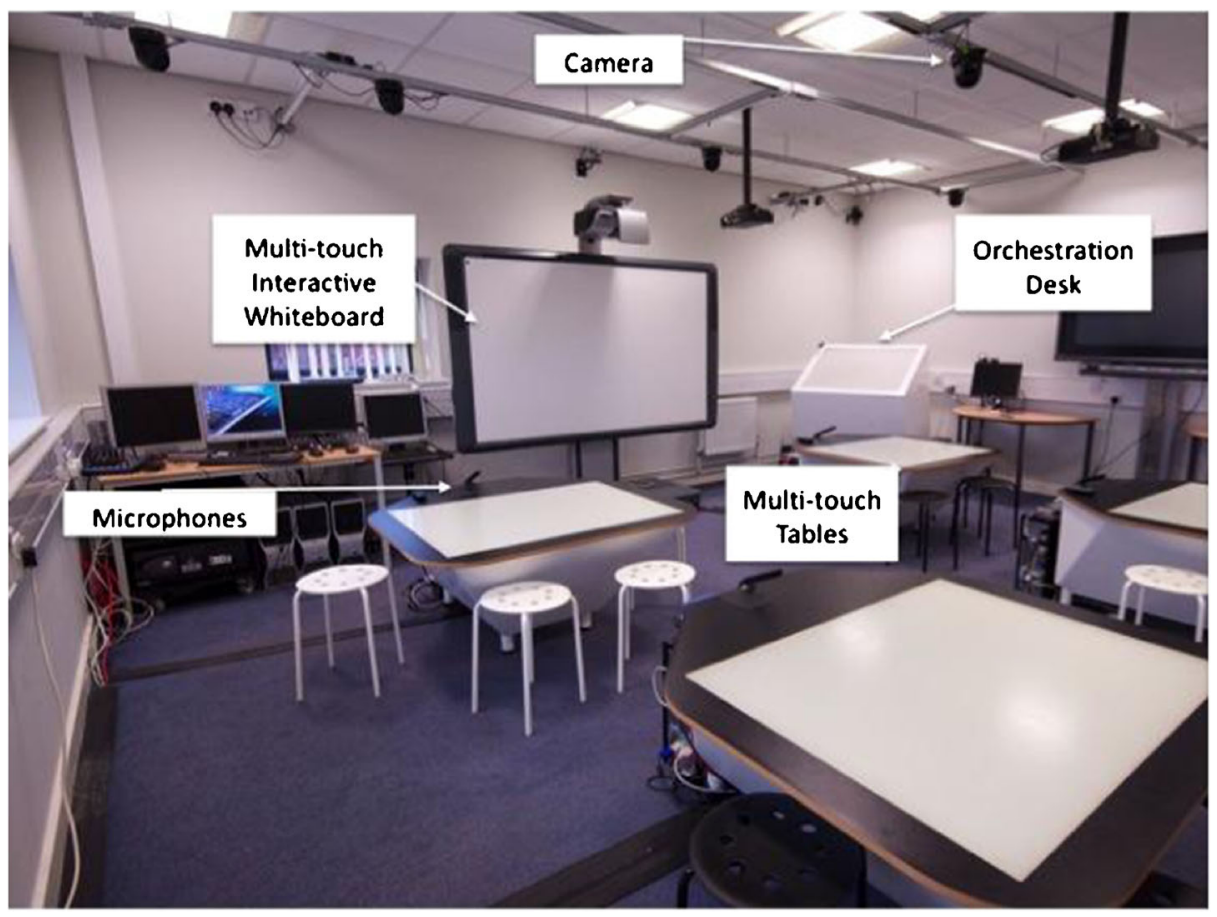

Fig. 2 Multi-touch classroom 
members all belonged to the same school and class. The students had been in the same class with their peers for the last few years in each of the schools. Thus, while students were pulled out of their normal classroom environment for the study, and were taught by new teachers, they were very familiar with their collaborators in the tasks. Informal feedback from their regular teachers in study two indicated that the activities and behavior of the students could be considered typical of their interactions in school.

Study one was designed to explore the nature of emergent leadership in the groups, to identify the distributed nature of the leadership and identify any systematic differences across the emergent leadership behaviors. These findings were then explored in a larger sample, and more typical classroom environment in the second study.

The research questions addressed in the two studies presented in this paper are:

1. What characterizes emergent leadership in collaborative learning groups, and are emergent leadership moves distributed across group members?

2. What are the different patterns of leadership moves within groups?

3. Does the distribution and pattern of leadership moves vary across content areas?

4. Is emergent leadership associated with task success?

\section{Study one}

Method

Participants were 32, year six pupils (mean age 10.6 years; $\mathrm{SD}=0.4$ years) who attended two local primary schools in England. There were 16 male and 16 female students in the sample. Participants were brought to the lab in groups of eight - four males and four females - and worked in same-gender groups of four. Participants were recruited from three classes in two schools (all groups came from the same classes). Both schools are ranked as average, or just below average, in England's standardized achievement system. Eight students were recruited from two year six classes in the first school, and 16 pupils were recruited from one classroom in the second school. For each of the three classes, two or three of the experimenters went to the classrooms, led the pupils through a series of mystery activities and introduced the multitouch tables with a video. Consent forms for parents were distributed; teachers selected participants from the students who returned signed consent forms.

Once each group of eight arrived at the lab, the students were divided into gender-matched groups of four. Both groups were simultaneously led through three activities that introduced them to the multi-touch table, with each group working on a separate table. The groups were then divided, so that one group completed a multi-touch version of the history mystery task, while the other group completed a paper-based version of the same task in another room. The groups were given a short break then switched rooms and conditions, completing a mathematics problem-solving task on either the multi-touch tables or paper.

\section{The task}

The tasks used for this study were based on a 'mystery' framework activity. One goal of framework activities is that they provide a similar structure to tasks, so that students and teachers can become familiar with them, and then different content can be added, allowing for the exploration of collaborative learning over time, while holding the tasks relatively constant. 
The mysteries framework activities were based on a pedagogical strategy created for the development and assessment of complex thinking in schools (Leat and Higgins 2002). During mystery tasks, groups of students are given a question, and clues that they need to make sense of in order to come to an answer to the question. Mysteries are designed to be open-ended, with the clues pointing to multiple possible answers, but the framework can also be used for problems that have a single right answer that the students need to determine through interpretation of the clues.

The history mystery used in this study is based upon an accident in a coal mine in 19th century north-east England - a location and period of history that was familiar to the children. The goal of the activity is for the students to come up with an answer to the question "What happened to Robert Dixon and whose fault was it?" By using the clues, the groups can engage in complex reasoning about what exactly happened, and who might be at fault. The task took a mean of $17.55 \mathrm{~min}$ to complete $(\mathrm{SD}=4.5 \mathrm{~min})$.

Three math word problems of a similar structure to the history mystery task were used in the math activity, all of which had a correct answer. The first task required the application of mathematical knowledge to eliminate all but the correct answer. In the second activity, the groups needed to order the clues, working through a series of mental calculations in the correct order to determine how much it would cost a fairground owner to provide prizes to every tenth person who went on a particular ride. The final math task was a logic problem, in recognition of the importance of logical reasoning and the solving of non-numerical word problems in mathematics, and as part of the mathematics curriculum in England (DfEE, 1999) and standards in the USA (NCTM 2000). The goal of this task was to match five fictional children with their food of choice after the school lunch trays had been mixed up. (See appendix for clues.) The format and content of the tasks was discussed with each of the teachers who confirmed that these were appropriate activities for their students and typical of the kinds of activities used in their schools. Together the three math tasks took a mean of $15.6 \mathrm{~min}$ to complete $(\mathrm{SD}=1.8 \mathrm{~min})$.

In the paper-based version of the task, clues were typed on small pieces of paper, which were placed in a pile in the center of the table at the beginning of the task. Generally, students shared the clues out amongst the group members, and took turns reading them aloud before moving on to solving the task. In the multi-touch version, the same clues were presented on digital slips of 'paper', which were placed in a pile in the center of the screen. The digital paper could be moved like normal paper to change orientation or change the location on the screen; the size could also be changed, allowing the groups to enlarge the clues to support joint attention, and to decrease the size of the clues they did not deem to be important. See Figs. 3 and 4 for an example of the set-up.
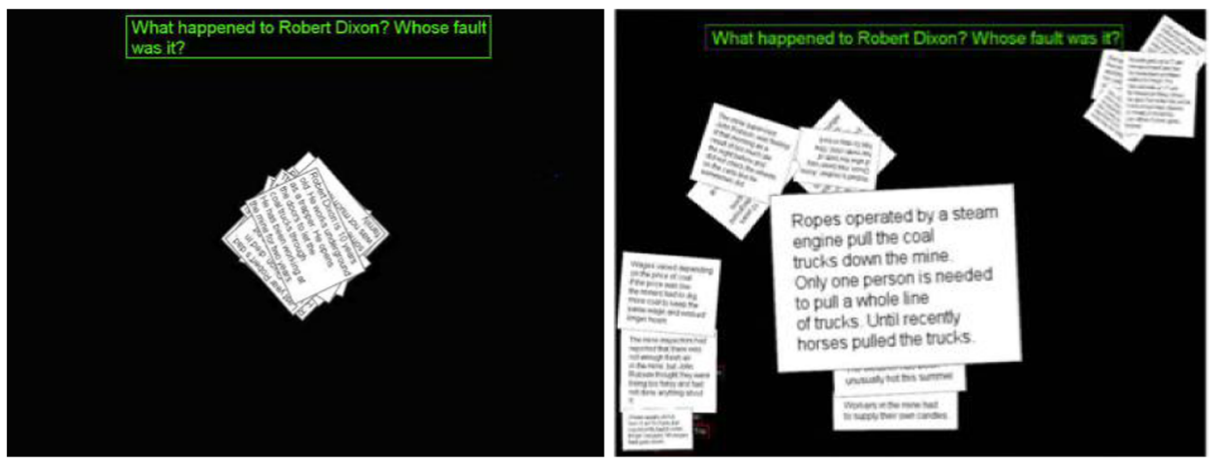

Fig. 3 Sreen shots from beginning and middle of the history task 

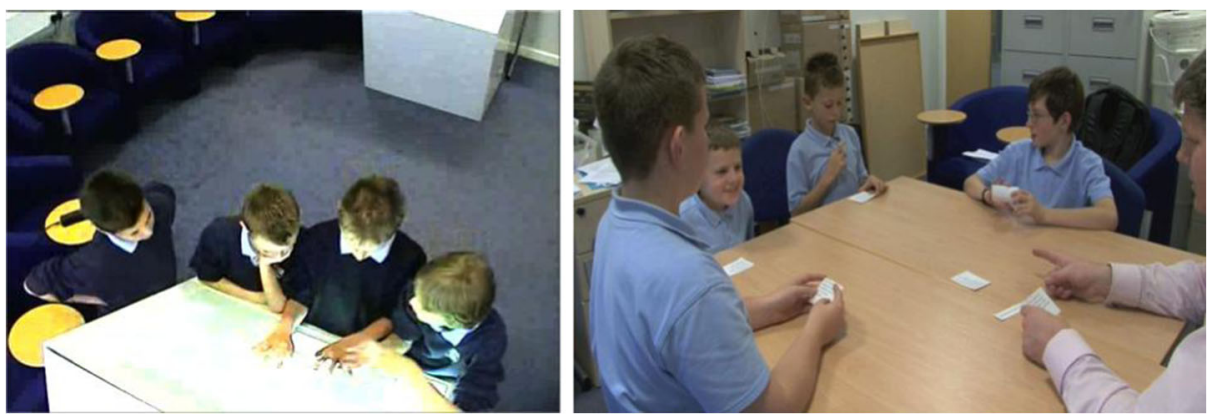

Fig. 4 Photographs of students in multi-touch and paper conditions

During study one, the teacher who worked with each group wrapped the task up when the groups had come to an answer, often helping them to solve the math tasks if they appeared to be stuck, and encouraging them to come to a conclusion in the history task if they were stalling. This help usually took the form of directing students to clues, or asking if all group members agreed with a comment. However, particularly in the math tasks, the teachers led the groups step-by-step through the tasks when they did not seem to be making any progress.

\section{Data}

All activities were videotaped and transcribed for analysis. Verbatim transcripts, formatted as a play script, were created for each video. In the analysis that follows, transcripts and video were used simultaneously.

\section{Analysis of leadership moves}

A coding scheme was adapted from Li et al. (2007) and is shown in Table 1. The unit of analysis was defined as a turn, and each code was only applied once to each turn, although more than one code could be applied to a single turn. Leadership moves were identified by turns that could be categorized as one of the five types of leadership from the coding scheme. The initial identification of leadership moves was conducted without regard for either the correctness or relevance of the move to the task content, and without attention to the reaction of other students in the group. However, in line with the perspective that leadership occurs in a multi-directional interactive manner among the group members, and drawing on Li et al. (2007), a second level of coding was applied. This coding identified successful and unsuccessful leadership moves by considering the moves immediately following the leadership code. Moves that accepted the leadership move resulted in the leadership move being coded as successful; moves that ignored the leadership moves resulted in the leadership move being coded as unsuccessful. All contributions, regardless of how correct they were in terms of reaching a solution for the task, could be classified as a leadership move or a move that accepted or rejected a leadership move. Examples of each leadership move are provided in Table 1, and the case study in study two provide further examples of each type of move.

The teacher's involvement differed between groups, and their attempts to take leadership were coded as teacher bids and are not discussed in this paper.

Due to the different nature of the tasks, the code 'Argument Development' from Li et al. (2007) was changed to Idea Management and Development, to provide a broader classification for turns that dealt explicitly with the ideas in the mysteries. Additionally, Acknowledgement 
Table 1 Leadership Coding Scheme

Code Definition Examples

Turn management Directing turn-taking; identifying who should make the next turn; announcing intent to take the next turn and monitoring or inviting participation.

\section{Planning \& Organizing}

Acknowledgement

Idea management $\&$ development

Topic control
Turns that recognized the value of another team-member's comments, or turns that reacted to a request for acknowledgement.

Statements that structured the activity or moves of the team or statements that attempted to keep the group on-task.

Development of the ideas, building upon previous ideas or proposing a solution (this is not used when students are jointly working on a solution). The correctness of the idea or proposed solution is not to be considered.

Moves that altered the direction of the conversation (about the task). This includes moves that take the group in a particular direction after a whole class discussion.
1. "Why don't you read that one out? And then, Tony, read that one." [speaker is directing other students to take turns]

2. "OK, Joe, you read that one. Read that one, and you [pointing]"

"I'll read this one?"

"Right; Joe, why don't you read yours first."

1. "Right, everyone line it up like we did before." [speaker is directing other students to organize the clues in a line]

2. "Right then, these two don't mean anything to us, so this is the rubbish corner." [student identifies two clues that they do not think are important that are together in the same part of the screen; he identifies this as the corner to put unwanted clues, a practice that is then followed by his team-mates.]

1. "Annie, do you think this is important? I do." [speaker is requesting acknowledgment of her idea from another student]

2. "This one's good, read this one Shannon" [student hands a clue she thinks is important to Shannon for her to evaluate it's importance. Shannon takes it, reads silently, then reads it aloud to the group.]

1. It doesn't explain whose... actually that does explain...look, look, the mine inspectors... that might explain whose fault it was because they thought he fell asleep...not enough air, not enough oxygen causes people to fall unconscious, so this should be in the not sure section "cause this does explain whose fault it might have been." [From history task: The student takes a clue, and describes how it relates to the question]

2. And you know about the candles, what happens if he wasn't rich enough so he couldn't afford it, 'oh where am I going, I don't know where I'm going' whack!" [From history task: Student refers to a clue that says the mine workers had to provide their own candles; he elaborates on what would happen if the workers did not have a candle, developing the argument that the boy in the mystery might have been unconscious at the time of the accident].

1. "How much will it cost the Waltzer owner for enough...enough cuddly monkeys for a day? How many cuddly monkeys do we need?" [From Waltzer: Student reads the question, and then interprets it to provide the next step for the group] 
Table 1 (continued)

\begin{tabular}{ll}
\hline Code & Examples \\
\hline Definition & $\begin{array}{l}\text { 2. "So now we need to decide if he was up } \\
\text { and healthy or whether he was, like, } \\
\text { unconscious" [From history task: student } \\
\text { summarizes the groups current position } \\
\text { and the decision they need to make to } \\
\text { come to a conclusion.] }\end{array}$ \\
\hline
\end{tabular}

was identified as both instances where a student acknowledged the contribution of another participant, and the instances where a student was asked for acknowledgment by another student. In the second case, acceptance of the leadership move was identified as occurring before the leadership move (e.g., the request for acknowledgment was seen as acceptance of the leadership move, assuming that the acknowledgment request was acted upon). The three math tasks were examined as a single task, and contrasted with the history tasks; the history task took about 15 to $20 \mathrm{~min}$, as did the three math tasks, giving us a comparable length of collaborative engagement to compare across content areas. One researcher coded all eight groups, while a second researcher coded two history and two math tasks, to assess reliability of the codes, with a reliability score of $86 \%$ (Cohen's Kappa=0.76). Disagreements were discussed until consensus was reached. Most disagreements occurred when differentiating between the codes Topic Control and Idea Management and Development (intellectual leadership), and between the codes Turn Management and Planning and Organizing (organizational leadership).

\section{Task success}

In both the history and math tasks, the teachers aimed to support the group as they worked towards a solution. In this way, all the groups successfully solved the math tasks (with different degrees of teacher support) and all groups came to an explanation on the history task. The quality of discussion on the history task was coded using the SOLO taxonomy (Biggs and Collis 1982). As reported elsewhere, there were few differences in the levels of reasoning reached across conditions (Higgins et al. 2012). As such, the outcomes on either the math or the history tasks will not be considered in relation to emergent leadership in study one.

\section{Results}

A total of 1,276 student utterances across all 8 groups $(M=159.5, \mathrm{SD}=59.66)$ were identified in the history task. One hundred and forty-eight utterances were identified as leadership moves $(11.5 \%)$ with a mean of 18.5 leadership moves per group $(\mathrm{SD}=8.4)$.

A total of 1,480 student utterances across all eight groups $(M=185, S D=53.4)$ were identified in the math tasks. Two hundred and five utterances were identified as leadership moves $(13.8 \%)$, with a mean of 25.6 leadership moves per group $(\mathrm{SD}=12.67)$.

\section{Distribution of leadership moves}

The distribution of leadership moves within each group is shown in Table 2, which shows the percentage of accepted leadership moves made by each group member (calculated 
Table 2 Percentage of leadership moves across all tasks and number of accepted leadership moves made by each participant in each content area

\begin{tabular}{|c|c|c|c|c|}
\hline & & $\begin{array}{l}\text { Percentage of } \\
\text { leadership moves } \\
\text { across all tasks }\end{array}$ & $\begin{array}{l}\text { Number of accepted } \\
\text { leadership moves } \\
\text { in history }\end{array}$ & $\begin{array}{l}\text { Number of } \\
\text { accepted leadership } \\
\text { moves in math }\end{array}$ \\
\hline \multirow[t]{4}{*}{ Group 1} & Child 1 & 29 & 6 & 11 \\
\hline & Child 2 & 17 & 4 & 6 \\
\hline & Child 3 & 26 & 7 & 8 \\
\hline & Child 4 & 27 & 12 & 4 \\
\hline \multirow[t]{4}{*}{ Group 2} & Child 1 & 34 & 4 & 9 \\
\hline & Child 2 & 24 & 0 & 9 \\
\hline & Child 3 & 13 & 4 & 1 \\
\hline & Child 4 & 29 & 5 & 6 \\
\hline \multirow[t]{4}{*}{ Group 3} & Child 1 & 4 & 1 & 0 \\
\hline & Child 2 & 22 & 5 & 0 \\
\hline & Child 3 & 17 & 1 & 3 \\
\hline & Child 4 & 56 & 1 & 12 \\
\hline \multirow[t]{4}{*}{ Group 4} & Child 1 & 32 & 12 & 12 \\
\hline & Child 2 & 53 & 15 & 24 \\
\hline & Child 3 & 5 & 1 & 3 \\
\hline & Child 4 & 9 & 0 & 7 \\
\hline \multirow[t]{4}{*}{ Group 5} & Child 1 & 37 & 3 & 4 \\
\hline & Child 2 & 5 & 0 & 1 \\
\hline & Child 3 & 42 & 4 & 4 \\
\hline & Child 4 & 16 & 0 & 3 \\
\hline \multirow[t]{4}{*}{ Group 6} & Child 1 & 34 & 6 & 10 \\
\hline & Child 2 & 57 & 6 & 21 \\
\hline & Child 3 & 2 & 0 & 1 \\
\hline & Child 4 & 6 & 2 & 1 \\
\hline \multirow[t]{4}{*}{ Group 7} & Child 1 & 18 & 3 & 4 \\
\hline & Child 2 & 45 & 10 & 7 \\
\hline & Child 3 & 21 & 6 & 2 \\
\hline & Child 4 & 16 & 2 & 4 \\
\hline \multirow[t]{4}{*}{ Group 8} & Child 1 & 39 & 2 & 14 \\
\hline & Child 2 & 32 & 11 & 2 \\
\hline & Child 3 & 7 & 0 & 3 \\
\hline & Child 4 & 22 & 3 & 6 \\
\hline
\end{tabular}

by dividing total accepted leadership moves made by that person, by total of all accepted leadership moves within the group). Over $90 \%$ (338 of 372) of leadership moves were accepted. 
The number and percentage of leadership moves differed between groups and participants. While some groups showed a balance of leadership moves across participants (e.g., group 1), in others one or two leaders emerged (e.g., group 3 or 4). Thus leadership moves appear to be distributed among group members, when data from all tasks is considered. However, this appears to be more complex when the data is broken down by discipline, with participants showing different amounts of leadership in the different disciplines (e.g., Child 2, Group 2, makes no leadership moves during the history task, but nine effective moves during the mathematics task).

Intellectual and organizational leadership in groups

The total number of accepted moves were calculated for each individual, and categorized into two types of leadership - intellectual and organizational. Intellectual leadership was determined by adding any turns that had been coded as Topic Control and Idea Management and Development, moves that moved the group on the cognitive or problem space aspects of the collaboration. Organizational leadership was calculated by adding turns coded as Planning and Organizing, Turn Management and Acknowledgment. These moves were identified as moves that support the group's interaction process, helping monitor and influence turn taking and participation.

As the goal of the study was to look at emergent leadership, rather than only focus on leadership moves, each type of leader was identified as the student who made the most accepted leadership moves in each category within each task. Groups where no one made more than 3 leadership moves in each category were identified as not having clear leadership. Similar to the work by Li et al. (2007), who identified leaders as the outliers in terms of number of leadership moves made, we chose the mean number of leadership moves per student per category (2.64; $\mathrm{SD}=3.09$ ) as the cut-off point for identifying leadership in study one. The cut-off also aligns with the qualitative differences between groups who have students who appear to be leaders, and groups where leaders cannot be identified.

Differences in leadership configurations are shown in Fig. 5. From this, it can be seen that in the history task, one group had a single leader, one group had distinct intellectual and organizational leaders, three groups only had an intellectual leader and three groups did not have a clear leader. In the math task, one person took on both leadership roles in two groups, three groups had distinct intellectual and organizational leaders, two groups only had an intellectual leader, and one group did not have any identifiable leader.

Across the tasks, there was some variability between groups, with one group showing no clear leadership in either content area, two groups who showed clear leadership in math but not

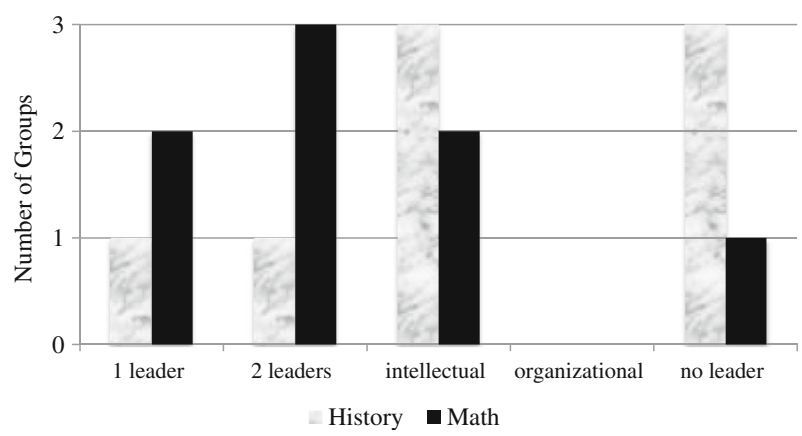

Fig. 5 Number of groups with different leadership configurations. Note: One leader indicates that one student took both roles; 2 leaders indicates that 2 different students each took one of the leadership roles (different intellectual and organizational leader) 
in history, three groups with different intellectual and organizational leaders across content areas, a group with shared leadership and a group with one leader across content areas. Figure 6 shows the distribution of each type of moves in each task for each participant.

Differences between intellectual and organizational leaders emerged in many of the groups, and across content areas. For example, in Group 1, Child 1 made the most organizational leadership moves during the history task (5 moves), while Child 4 made most of the
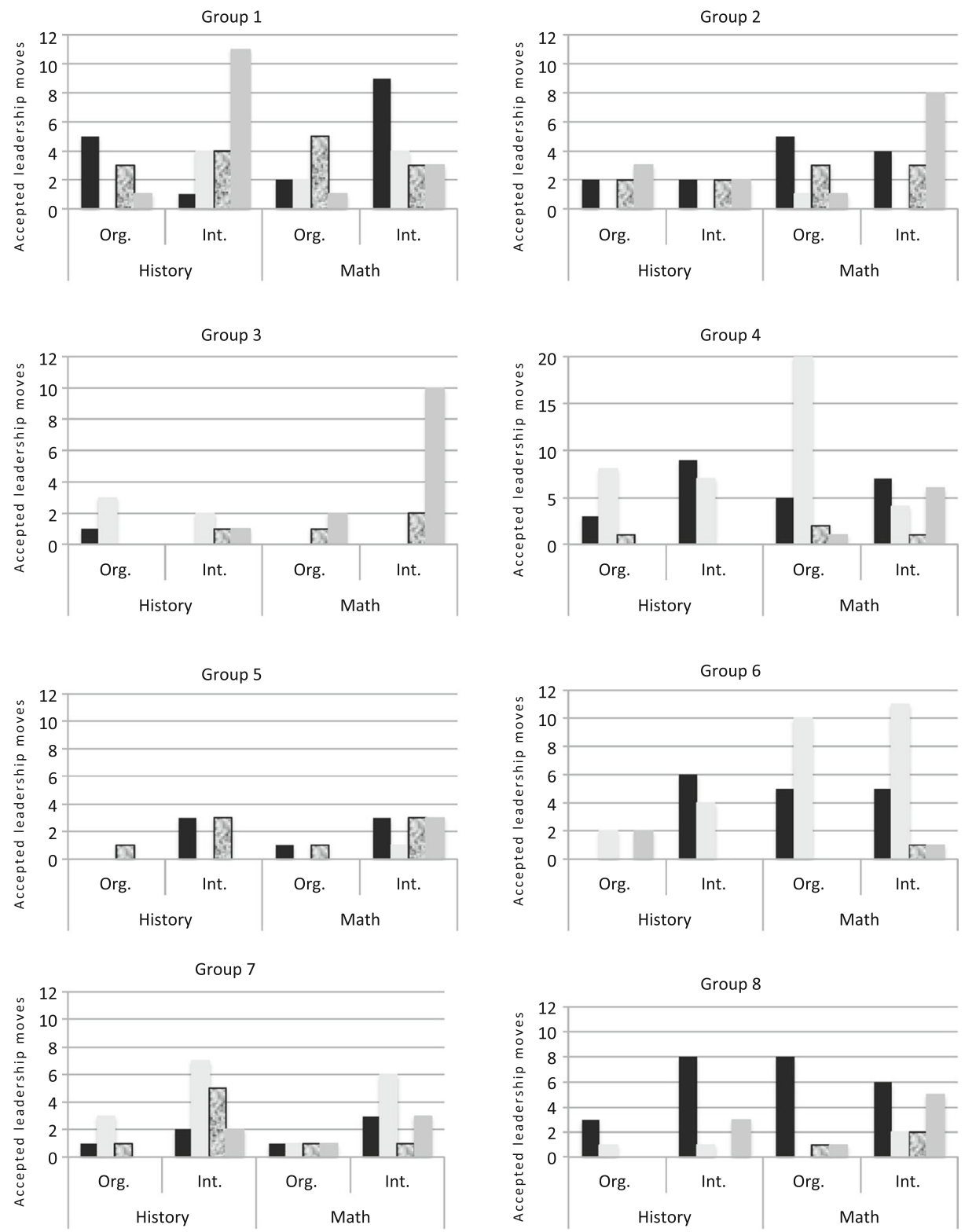

Child 1

Child 2

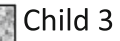

Child 4

Fig. 6 Number of accepted organizational and intellectual moves by group 
intellectual leadership moves (11). However, during the math tasks, Child 1 made more of the intellectual leadership moves (9), while organization was more shared, with Child 3 taking slightly more leadership than his team-mates (5).

This is contrasted with a number of groups where there was clear leadership in the math tasks, but not during the history task. For example, in Group 3, there were virtually no leadership moves during the history task, while Child 4 assumed the role of intellectual leader in the math task (10 moves). This was more striking in Group 6, which again had few leadership moves in the history task, while one group member, Child 2, took clear organizational (10) and intellectual leadership (11) during the math task.

In other groups, both forms of leadership were expressed by one or more group members. In Group 4, Child 2 took clear organizational leadership in both content areas, although she also made a number of intellectual leadership moves, particularly in the math task. The intellectual leadership was shared, however, with two other group members - with Child 1 in the history task, and with Child 1 and Child 4 in the math task. A similar pattern is seen in Group 8, where Child 1 took intellectual leadership in both history and math tasks, but also took a much clearer organizational role in the math tasks than he or any of his group members did in the history task.

\section{Differences across condition}

To examine whether there were differences in the number and types of leadership moves made across the conditions, the data were examined by task (math or history) and condition (multitouch or paper). Results indicate that the number of moves was almost identical across conditions, indicating that the technology did not have an obvious influence on the leadership behaviors of group members. Descriptive statistics are presented in Table 3.

\section{Summary of study one}

In study one, we explored emergent leadership in eight groups of students, each working with a teacher present. Initial results indicated that leadership was distributed across the members of each group, although the patterns of emergent leadership differed across disciplinary areas. Two types of leadership - intellectual and organizational leadership - were identified as accounting for different leadership behaviors in the teams. The results showed that in some groups there was a pattern of distributed leadership, and that the distributions of the leaders appeared to fall along the lines of intellectual and organizational leader. Three of the eight groups in the math activity had a distinct intellectual and organizational leader, while in two groups, both roles were held by the same student. While this was less evident in the history

Table 3 Mean (SD) of leadership moves across conditions

\begin{tabular}{llll}
\hline & Total Moves & $\begin{array}{l}\text { Accepted } \\
\text { Organizational }\end{array}$ & $\begin{array}{l}\text { Accepted } \\
\text { Intellectual }\end{array}$ \\
\hline $\begin{array}{l}\text { Math } \\
\text { Multi-touch }\end{array}$ & $27.5(14.45)$ & $11.25(11.59)$ & $14.5(2.65)$ \\
$\quad$ Paper & $26(9.75)$ & $9.25(5.37)$ & $15.5(4.04)$ \\
$\begin{array}{l}\text { History } \\
\text { Multi-touch }\end{array}$ & $19(9.38)$ & $4.5(3.32)$ & $12(5.89)$ \\
Paper & $20(8.6)$ & $7(3.56)$ & $10.5(6.4)$ \\
\hline
\end{tabular}


task, there were also fewer leadership moves made during the history activity. Additionally, although the organizational behaviors of a leader are more often seen as important, the results from our analysis indicate that there were groups that only had an intellectual leader, while there was no group that had an organizational but not an intellectual leader.

These findings suggest that emergent leadership may be considered to be two separate constructs, although, at times, both roles may be held by one person. In the second study, we examined this further, in a classroom laboratory, to explore the patterns of distribution of emergent leadership in children's collaborative learning groups.

\section{Study two}

Method

Participants were 96 year six pupils (mean age 10.58 years; $\mathrm{SD}=0.39$ years) who attended six local primary schools. There were 48 male and 48 female students in the sample. Participants were brought to the lab in groups of sixteen - eight males and eight females. Groups from four of the schools worked in same-gender groups, while groups from two schools worked in mixed gender groups (two male and two female students). Thus there were eight all-male groups, eight all-female groups and eight mixed-gender groups in the sample. However, due to technical issues, some of the data from one male and one female group were not recorded, and so they are excluded from this analysis, leaving us with 22 groups in this study (seven all male, seven all female and eight mixed gender groups).

Six schools were invited to participate in the study. All the schools who participated are ranked as average, or just below average, on standardized tests of academic achievement in England. For each of the schools, two or three of the experimenters went to their classrooms and led the pupils through similar orientation activities to those used before the first experiment. Parental consent forms were distributed, and teachers selected the students who could attend from those who returned consent forms. Teachers were asked to randomly select 8 male and 8 female children to attend. Return rates of consent forms were high in most schools, and informally a number of teachers mentioned that they had been more inclined to select the better behaved or higher-achieving children to participate, either in an effort to reward certain students, or to ensure their school was well represented. All participants were selected from the same class group in all six schools.

\section{The task}

The same history and mathematics tasks were also used in study two, however all tasks were completed in the multi-touch classroom (see Fig. 2). After completing initial exercises to familiarize the students with the multi-touch tables, they completed the history task; students then had a short break before returning to the classroom to complete the three math activities. The history task took about half an hour to complete $(\mathrm{M}=28.3 \mathrm{~min} ; \mathrm{SD}=3.9 \mathrm{~min})$, while the three math tasks took less than half an hour $(\mathrm{M}=23.5 \mathrm{~min} ; \mathrm{SD}=2.7 \mathrm{~min})$.

While the tasks were the same as in study one, the classroom lab meant that, rather than having a teacher with each group, a single teacher ran the class, introducing the activity, sending the mystery to the students from the orchestration desk, and moving between groups to monitor progress. The teacher could freeze all the tables at any stage, and project the contents of any table onto an interactive whiteboard. The protocol that the teachers followed was to introduce the topic, send the mystery to the student tables, lock the tables after a short 
time to make sure everyone knew what they were doing, allow the groups to resume, and then pause once or twice more for mini-plenary sessions and a final discussion of the task. During the discussion and mini-plenary sessions, the teacher projected the content from one of the tables, and prompted the groups to explain their solution. Both teachers (members of the research team) who participated in Study One, participated in Study Two, with each teacher teaching three classes in the classroom.

\section{Data}

The classroom is designed for data collection of group interaction, allowing for video recording of each group from two angles, and audio recording from a microphone embedded in each table. The teacher was recorded with a radio microphone and a fishbowl camera was used to record the entire classroom. The teacher audio stream was transcribed, and the audio from each group was transcribed; the teacher transcript was then integrated into the groups' transcripts. Using a tool developed by the team transcripts were created along a time-line, producing time-stamped information for each turn. The coding for this study was conducted using printed copies of the transcripts, laid out in play script format, while also viewing the videos of the groups and the tables.

\section{Coding}

The coding scheme described in study one was used again for study two (see Table 1), with all transcripts coded for the five moves, and each move identified as either accepted or rejected. The transcript for each group was coded separately, while watching the videos of the group. Due to the different nature of collaboration within a classroom, additional rules were defined for coding this data. Coding only occurred when the tables were unlocked for use; therefore coding began at the moment the teacher sent the mystery to the tables and unlocked it for use, and no coding occurred during whole-class discussions. Additionally, coding was not applied to groups while the teacher was directly speaking to that group (this was identified as teacher interaction). We note that students interact differently in the presence of the teacher, and the role of group spokesperson (both during the activity and whole-class discussion) appears to be different from the leadership described in this paper, however, exploring this role is beyond the scope of this paper.

Two authors coded the transcripts, with a reliability score of $87 \%$ on $10 \%$ of the transcripts $($ Cohen's Kappa=0.86). Disagreements were discussed until consensus was reached.

\section{Success on math tasks}

While in study one each group was directly supported by a teacher, in the second study there was only one teacher present for each class of 16 students. As such, the outcomes on the math tasks differed between groups. Progress on solving the tasks were coded using a four-level coding scheme, to identify groups who made no progress, little progress, some progress, and successfully solved the problems. Two authors coded two groups in each task, with a reliability of $83 \%$ across the six transcripts (Cohen's Kappa=0.67). In order to simplify the data, tasks where no or little progress was made were grouped together, and were given a score of zero. Tasks that were identified as good progress or solved were classed as successful, and were given a score of one. The total number of successful tasks was calculated for each group, with potential range between 0 and 3 . 


\section{Success on history task}

The history mystery was not designed to have a single correct answer, but to engage the students in historical reasoning, using the evidence to build an argument. To understand the success of each group, the utterances were coded using the SOLO coding scheme (Biggs and Collis 1982) to identify the levels of reasoning (See Higgins et al. 2012, for a description of the coding scheme). To assess success, the highest level of the SOLO coding scheme reached during small group conversation was identified for each group. Two of the authors coded three of the 22 transcripts, with agreement on $89 \%$ on the SOLO codes (Cohen's Kappa $=0.67$; Weighted Cohen's Kappa=0.74).

\section{Results}

Distribution of leadership moves within groups

During the history task, the mean number of utterances each student made was 56.6 $(\mathrm{SD}=22.32)$. The mean number of accepted leadership moves was $5.9(\mathrm{SD}=5.6)$ and mean number of rejected leadership moves was $1.38(\mathrm{SD}=1.52)$. During the math tasks, the mean number of utterances per student was $69.83(\mathrm{SD}=29.56)$, with a mean of $6.91(\mathrm{SD}=5.77)$ accepted leadership moves and $1.47(\mathrm{SD}=1.6)$ rejected leadership moves.

The total number of accepted and rejected moves were calculated for each individual. A total of 1,377 leadership moves were identified from 11,126 utterances across the 22 groups ( $12 \%$ of utterances were coded as leadership moves); 1,127 or $82 \%$ of leadership moves were accepted. Table 4 shows the percentage of accepted leadership moves made by each group member and the number of accepted and total leadership moves made in each content area (groups are identified by the color of their table). The total number of leadership moves per group ranged from 12 to 91 (Mean=57.38; $\mathrm{SD}=18$ ). Groups also differed in the distribution of leadership moves. Groups were categorized by groups that showed one strong leader and no other leaders, groups that have one main and one secondary leader and groups who showed shared leadership. The number of groups that correspond to each of these categories are show in Table 5.

\section{Intellectual and organizational leadership in groups}

In study one, two types of emergent leadership were identified to describe the way in which leadership was distributed among group members. The two codes that made up intellectual leadership (Topic Control and Idea Management and Development) and the three that were categorized as organizational leadership (Planning and Organizing, Turn Management and Acknowledgment) were collapsed in the study two data, to examine whether the same pattern emerged. This analysis was conducted by content area (i.e., groups were examined within history and math separately; shown in Table 6).

As in study one, a minimum of three accepted leadership moves was required to be counted as a leader for both organizational and intellectual leadership, which falls around the mean for accepted leaderships moves for both types of accepted leadership. If no person in a group made three or more organizational leadership moves, the group was considered as not having an organizational leader; the same criteria were used for intellectual leaders. Once leadership was determined, the group member who made the most accepted leadership moves was identified as the leader of that group. Thus groups were identified as having no leader, only an 
Table 4 Percentage of Total Leadership Moves by school and group

\begin{tabular}{|c|c|c|c|c|c|}
\hline & & Table & & & \\
\hline \multicolumn{2}{|l|}{ School } & Yellow & Green & Red & Blue \\
\hline \multirow[t]{4}{*}{ Yadstone } & Child 1 & 37.5 & 17 & 25 & 13 \\
\hline & Child 2 & 9 & 50 & 33 & 32 \\
\hline & Child 3 & 16 & 10 & 17 & 42 \\
\hline & Child 4 & 37.5 & 23 & 25 & 13 \\
\hline \multirow[t]{4}{*}{ Seacrest } & Child 1 & 28 & 20 & 11 & 28 \\
\hline & Child 2 & 10 & 7 & 8 & 6 \\
\hline & Child 3 & 10 & 48 & 74 & 44 \\
\hline & Child 4 & 51 & 24 & 7 & 22 \\
\hline \multirow[t]{4}{*}{ Shadbrook } & Child 1 & 10 & 50 & 70 & 2 \\
\hline & Child 2 & 43 & 10 & 18 & 58 \\
\hline & Child 3 & 34 & 15 & 7 & 2 \\
\hline & Child 4 & 13 & 25 & 5 & 38 \\
\hline \multirow[t]{4}{*}{ Easterburn } & Child 1 & 45 & 24 & 42 & 31 \\
\hline & Child 2 & 8 & 19 & 21 & 31 \\
\hline & Child 3 & 28 & 44 & 8 & 17 \\
\hline & Child 4 & 19 & 12 & 30 & 20 \\
\hline \multirow[t]{4}{*}{ Benbrook } & Child 1 & 5 & 7 & 14 & 11 \\
\hline & Child 2 & 16 & 22 & 25 & 17 \\
\hline & Child 3 & 67 & 55 & 53 & 42 \\
\hline & Child 4 & 12 & 15 & 8 & 29 \\
\hline \multirow[t]{4}{*}{ Dunhulme } & Child 1 & & 2 & 14 & \\
\hline & Child 2 & & 5 & 16 & \\
\hline & Child 3 & & 56 & 54 & \\
\hline & Child 4 & & 37 & 16 & \\
\hline
\end{tabular}

intellectual leader, only an organizational leader, both an intellectual and an organizational leader, and a leader who took both organizational and intellectual leadership. The number of groups who were categorized as each type is displayed in Fig. 7.

Table 5 Leadership distribution patterns in study two

\begin{tabular}{llc}
\hline Category & Definition & $\begin{array}{c}\text { Number of } \\
\text { Groups }\end{array}$ \\
\hline One leader & One participant over 65\%; no-one else over 20\% & 3 \\
One main and secondary leader(s) & $\begin{array}{l}\text { One participant over 45 \%; one or more participants } \\
\text { between } 15 \text { and 30 \% }\end{array}$ & 10 \\
Shared leadership & $\begin{array}{l}\text { Groups with two or more participants with similar } \\
\text { percentages of leadership and no-one over 50\%. }\end{array}$ & 9 \\
\hline
\end{tabular}


Table 6 Descriptive statistics for individuals by task

\begin{tabular}{lll}
\hline & History & Math \\
\hline Total moves & $7.27(6.04)$ & $8.38(6.24)$ \\
Total accepted moves & $5.96(5.63)$ & $6.91(5.78)$ \\
Total rejected moves & $1.38(1.52)$ & $1.47(1.6)$ \\
Total accepted organizational moves & $3.18(3.79)$ & $2.56(2.84)$ \\
Total accepted intellectual moves & $2.72(2.83)$ & $4.19(3.94)$ \\
Total rejected Organizational moves & $0.55(0.97)$ & $0.34(0.68)$ \\
Total rejected intellectual moves & $0.83(1.13)$ & $1.13(1.34)$ \\
\hline
\end{tabular}

Leadership across task type

To examine whether there were differences in the amount and type of leadership across the math and history tasks, a multivariate ANOVA was conducted with content area as the independent variable and total leadership moves, accepted organizational leadership, and accepted intellectual leadership as dependent variables. This analysis was conducted on the group-level data (although results are similar when the individual level data is examined). The results showed that there was a significant main effect of content area on total number of accepted intellectual moves, $F(1,39)=7.9$, $p=0.008, \eta^{2}=0.17$, with more accepted intellectual leadership moves in the math tasks $(\mathrm{M}=15.9, \mathrm{SD}=1.28)$ than in the history task $(\mathrm{M}=10.85, \mathrm{SD}=1.25)$. The effect of content area on total moves was not significant, $\mathrm{F}(1,39)=0.45, p=0.5, \eta^{2}=0.01$, and nor was the effect of content area on total accepted organizational moves, $F(1,39)=$ 2.92, $p=0.09, \eta^{2}=0.07$.

To determine whether the person taking on the role of leader remained stable across the two tasks, each type of leader was identified for each group and each task, and compared. The results indicated that leadership remained unchanged across history and math in four groups; in six groups both the intellectual and organizational leader changed between history and math. Six groups had a change in the organizational leader but not intellectual, and six groups had a change in the intellectual leader, but not the organizational leader.

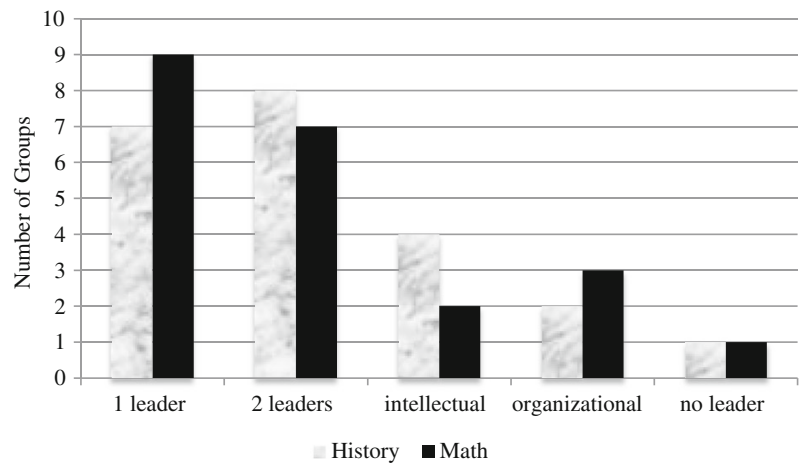

Fig. 7 Leadership types by content area. Note: One leader indicates that one student took both roles, while 2 leaders indicates that 2 different students each took one of the leadership roles (different intellectual and organizational leaders) 


\section{Leadership and group outcomes}

The success of groups on the math tasks was calculated by grouping tasks where little or no progress was made and tasks where good progress or a solution was found. Each group then received a score between zero and three to show how many tasks they had come close to solving. Two groups scored zero across all three tasks, four groups scored one, eight groups made good progress on two of the tasks, while eight groups made good progress on all three tasks. As success is a group level measure, the association with leadership moves was evaluated in terms of number of moves per group, rather than looking at leadership at the individual level. Descriptive statistics are shown in Fig. 8, which indicate that the number of intellectual leadership moves increase with task success, but that organizational leadership is highest in the least successful groups.

In order to conduct analysis about the differences between groups, the number of leadership moves per group were categorized into high, medium and low moves per group for each of total accepted moves, total intellectual moves and total organizational moves. Table 7 provides information about the number of moves in each category. Chi square analyses were conducted to examine the relationship between number of moves per group and number of tasks that the group solved. Results indicate that there was no significant relationship for total accepted leadership moves, $\chi^{2}(N=22)=7.12, p=0.31$, or for total accepted organizational moves, $\chi^{2}(N=22)=8.84, p=0.18$. The relationship between total accepted intellectual moves and task success was significant at the $10 \%$ level, $\chi^{2}(N=22)=12.47, p=0.052$.

To further evaluate if success was influenced by type of leadership move, median splits were conducted for each of the fives moves. Results indicated that the relationship between Turn Management and success was significant ( $5 \%$ level), $\chi^{2}(N=22)=9.9, p=0.019$. However, as can be seen in Table 8, seven groups who were high on turn management answered two of the three problems correctly, while seven who were low on this category solved all three of the tasks. This is likely to be influencing the analysis, and it should be interpreted with caution.

Results also indicated a significant relationship between Idea Management and Development and success, $\chi^{2}(N=22)=10.9, p=0.012$. The analysis did not indicate any other significant relationship between leadership moves and task success. Table 8 shows the number of groups in each category for each leadership move and their success on the tasks.

For the history task, the utterances of each group were coded using the SOLO taxonomy to evaluate the level of reasoning reached during the task. The highest level of reasoning was used as a proxy for group success, with groups getting a score of between 1 (pre-structural) and 5 (extended abstract). Three groups received a score of 2 (uni-structural), indicating they got no further than reading the clues and making basic comments about the value of each clue.

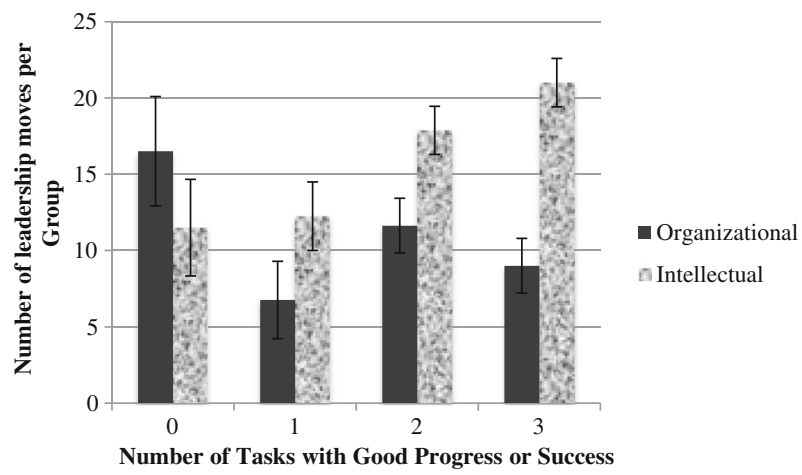

Fig. 8 Mean number of leadership moves per group by task success 
Table 7 Number of accepted leadership moves in high, medium and low leadership groups

\begin{tabular}{|c|c|c|c|c|c|c|}
\hline & \multicolumn{2}{|l|}{ Low } & \multicolumn{2}{|c|}{ Medium } & \multicolumn{2}{|l|}{ High } \\
\hline & Moves & $\begin{array}{l}\text { Number } \\
\text { of groups }\end{array}$ & Moves & $\begin{array}{l}\text { Number } \\
\text { of groups }\end{array}$ & Moves & $\begin{array}{l}\text { Number } \\
\text { of groups }\end{array}$ \\
\hline & & & \multicolumn{4}{|c|}{ Mathematics } \\
\hline Total leadership & $6-23$ & 8 & $24-30$ & 7 & $31-47$ & 7 \\
\hline Organizational & $1-7$ & 7 & $8-10$ & 8 & $11-21$ & 7 \\
\hline \multirow[t]{2}{*}{ Intellectual } & $5-14$ & 7 & $15-19$ & 7 & $20-28$ & 8 \\
\hline & & & History & & & \\
\hline Total leadership & $6-17$ & 7 & $18-27$ & 7 & $28-52$ & 8 \\
\hline Organizational & $3-9$ & 8 & $10-14$ & 7 & $15-31$ & 7 \\
\hline Intellectual & $1-7$ & 7 & $8-12$ & 8 & $13-22$ & 7 \\
\hline
\end{tabular}

Eight groups had a maximum reasoning level of 3 (multi-structural), indicating that group members were making connections between two of the clues, but not building a clear argument. Six groups reached level four (relational), using two or more clues to build an argument, while five groups reached level five (extended abstract), bringing together multiple clues to support their argument. Descriptive statistics in Fig. 9 indicate that the highest levels of leadership were associated with groups who reached the highest level of reasoning. However, the groups who showed the second highest level did not progress passed the uni-structural level which was defined as merely making comments on the value of each clue in isolation. Groups who reached the third and fourth levels of reasoning show less leadership.

In order to conduct analysis about the differences between groups, the numbers of leadership moves per group were categorized into high, medium and low moves per group for each of total accepted moves, total intellectual moves and total organizational moves. Table 7 provides information about the number of moves in each category. Chi square analyses

Table 8 Number of groups in each category of number of leadership moves and task success

\begin{tabular}{|c|c|c|c|c|c|c|c|c|c|c|}
\hline & \multicolumn{2}{|c|}{ Turn Management } & \multicolumn{2}{|c|}{$\begin{array}{l}\text { Planning \& } \\
\text { Organizing }\end{array}$} & \multicolumn{2}{|c|}{ Acknowledge } & \multicolumn{2}{|c|}{$\begin{array}{l}\text { Idea Management \& } \\
\text { Development }\end{array}$} & \multicolumn{2}{|c|}{ Topic Control } \\
\hline & Low & High & Low & High & Low & High & Low & High & Low & High \\
\hline Solved tasks & & & & & \multicolumn{4}{|c|}{ Mathematics } & & \\
\hline 0 & 1 & 1 & 0 & 2 & 1 & 1 & 2 & 0 & 2 & 0 \\
\hline 1 & 3 & 1 & 3 & 1 & 3 & 1 & 4 & 0 & 1 & 3 \\
\hline 2 & 1 & 7 & 3 & 5 & 6 & 2 & 3 & 5 & 4 & 4 \\
\hline 3 & 7 & 1 & 5 & 3 & 4 & 4 & 1 & 7 & 4 & 4 \\
\hline SOLO code & & & & & \multicolumn{4}{|c|}{ History } & & \\
\hline 2 & 1 & 2 & 2 & 1 & 2 & 1 & 2 & 1 & 0 & 3 \\
\hline 3 & 3 & 5 & 4 & 4 & 3 & 5 & 4 & 4 & 5 & 3 \\
\hline 4 & 3 & 3 & 5 & 1 & 2 & 4 & 4 & 2 & 2 & 4 \\
\hline 5 & 1 & 4 & 1 & 4 & 2 & 3 & 0 & 5 & 2 & 0 \\
\hline
\end{tabular}




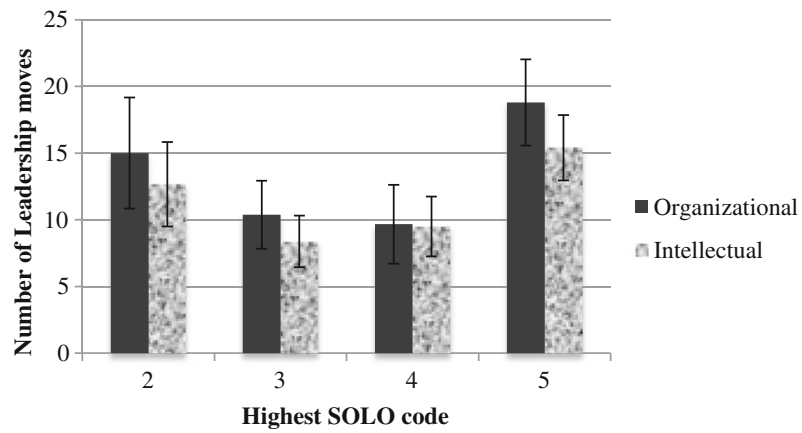

Fig. 9 Mean Number of leadership moves per group by SOLO level

were conducted to examine the relationship between number of moves per group and the highest level of reasoning reached within the group. Results indicate that there was no significant relationship for total accepted leadership moves, $\chi^{2}(N=22)=6.15, p=0.41$, or for total accepted organizational moves, $\chi^{2}(N=22)=4.57, p=0.6$, or intellectual moves, $\chi^{2}(N=22)=6.87, p=0.33$.

To further evaluate if level of reasoning was influenced by the types of leadership moves, median splits were conducted for each of the fives moves. Results indicated no significant relationship between level of reasoning and any of the five leadership moves.

\section{Case study}

The group of four boys from Yadstone school who worked at the green table provide an example of a group where leadership moves are distributed, showing evidence for different types of leadership roles and changes across task types. Across both tasks, eight of Jack's moves were accepted, twenty-six of Tom's, five of Daniel's and eleven of Callum's. Thus it appears that while Tom was the primary leader, the rest of the group made a range of leadership moves that were also accepted.

As shown in Table 9, however, when the leadership moves are broken down by content area and when intellectual and organizational moves are examined separately, the picture is more complex, with Tom's leadership being most evident in the math task, and associated with intellectual moves, while Callum and Tom both take organizational leadership roles. Tom and Jack appear to share leadership in the history task, although here Tom takes more of an organizational lead, where Jack makes the most intellectual moves.

Table 9 Yadstone Green's Accepted Leadership Moves

\begin{tabular}{llllll}
\hline & \multicolumn{1}{l}{ History } & & & Math \\
\cline { 2 - 3 } \cline { 5 - 6 } & Intellectual & Organizational & & Intellectual & Organizational \\
\hline Jack & 5 & 1 & 2 & 0 \\
Tom & 2 & 4 & 13 & 5 \\
Daniel & 0 & 2 & 2 & 1 \\
Callum & 0 & 3 & 2 & 6
\end{tabular}




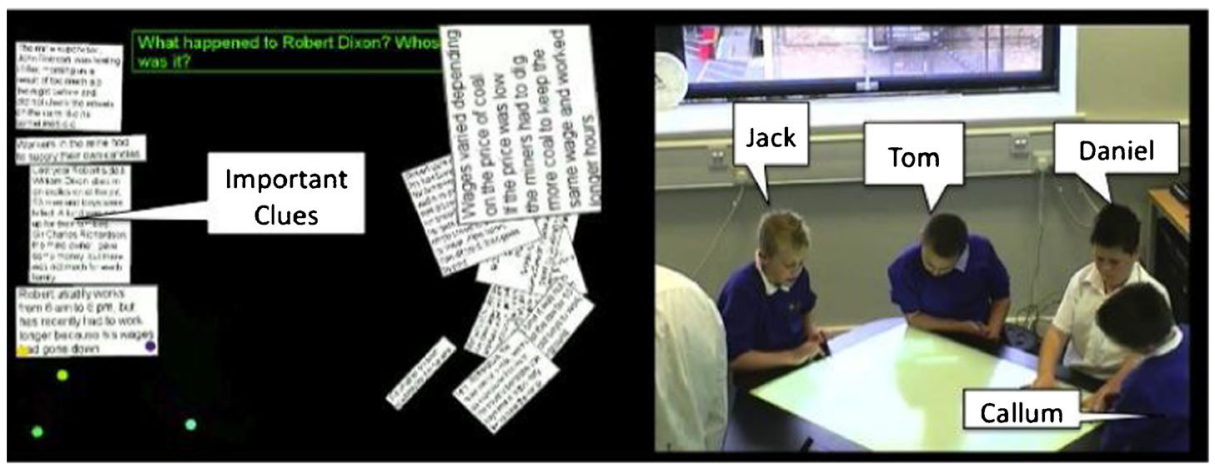

Fig. 10 Yadstone Green working on the history task

Distributed leadership moves in history

During the history task the students are trying to work out what happened to Robert Dixon and whose fault it was. They have been told that his leg was amputated after a mining accident, which happened when he fell asleep down in the pit. In the extract below, the students are looking at the clues that describe the influence of the price of coal on the miners' wages, and how when they had lower wages, they had to work even longer hours than usual (which would mean Robert was tired and could have fallen asleep, although the students need to decide whether it was his fault for falling asleep, or due to the falling price of coal and unstable wages). This extract begins after a number of failed bids by Tom to get the group's attention as they were focused on the construction activity that was going on outside the classroom window. By reading the clue, Tom gets the group to re-engage in the task, and they begin to consider how having to work longer might have affected Robert Dixon.

During this extract, we see the group work together, with Tom, and then Jack taking intellectual leadership moves to explore the clues and help create an argument. Daniel takes an organizational role, making sure the clues are arranged in a particular manner on the table, so they can return to the ideas they thought were important at a later time (see Fig. 10).

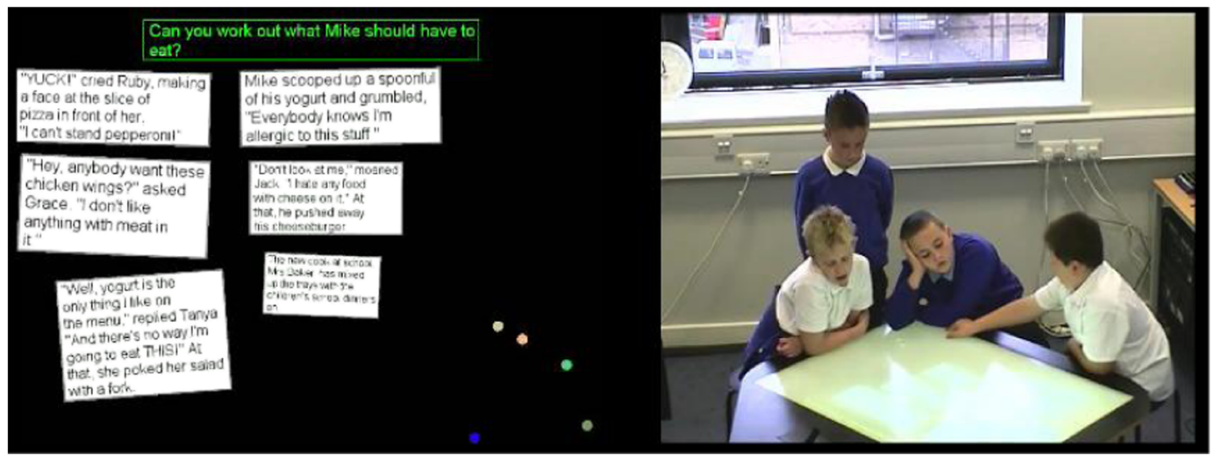

Fig. 11 Yadstone green working on the Dinner Disasters Task 
Tom "Robert usually worked from six am to six pm but recently had to work longer because his wages had gone down" [reading clue]. That can be one. Jack that's one! He used to work there but he's had to work more' cause his wages have gone down.

Jack That's another one, Callum. [passes the clue Tom has just read across the table]

Daniel "Robert usually worked..." put that in place for us please. [reads the clue as Jack passes it across the table, then asks Callum to position it with the other important clues]

Tom "Wages vary depending on the price of coal. If the price was low then miners had to dig more coal to keep the same wage" This is important, it's about the wages, read it. I think it's important anyway. This one definitely. [passes clue to Jack for his opinion]

Jack The price of coal is very low, so they might not earn enough [having read the clue silently, Jack interprets it for the group and identifies why it might be important to their reasoning]

Tom That's what I've just said [agreeing with Jack's interpretation of the clue, Accepting Jack's move even though he didn't rephrase it in this manner].

\section{Distributed leadership moves in mathematics}

The second extract is taken from the beginning of the logic problem 'Dinner Disaster', a task where the students have to work through five clues, each of which states which food a fictional child has, and a reason why they do not want that food. The clues can be linked together in such a way as to determine what each child should eat, and finally to answer the question of what Mike will have for his dinner. The group starts off with Callum organizing the clues so that everyone can see them, while Daniel manages who will read each clue. After reading through most of the clues, Tom makes a number of attempts to draw the group into the goal of the task, namely, deciding what Mike should have to eat. Although his first attempt at controlling the discussion is rejected by Jack, who has still to read his clue aloud, Daniel accepts his next bid for leadership, and starts to work with him to consider the possibilities (see Fig. 11).

Callum Put it in the top corner [directing the organization of the clues, which Planning \& Organizing the rest of the students help with]

Daniel There's one, there's one for Jack to read; there's one for Tom to read Turn management [distributing the clues among the group]

Callum Turn them right round, it's easier like that [directing the group to turn the clues so everyone can see them]

Daniel There's one for me [continuing to distribute clues]

Tom Mike's allergic to yogurt, it can't be yogurt. [having silently read the clue Daniel passed him, Tom summarizes it for the group]

Group reading clues and off topic

Tom Right, what should Mike have to eat?

Jack 'Hey, anybody want these chicken wings, asked Grace, I don't like anything with meat in it" [reading clue]

Tom What, "Can you work out what Mike should have to eat?" [reading question] Well Mike could have pepperoni pizza [makes a suggestion]

Planning \& organizing [continued from above]

Turn management [continued from above]

Idea management \& development

Topic control [rejected]

Ignores Tom's attempt to control topic

Topic control [accepted by Daniel] 


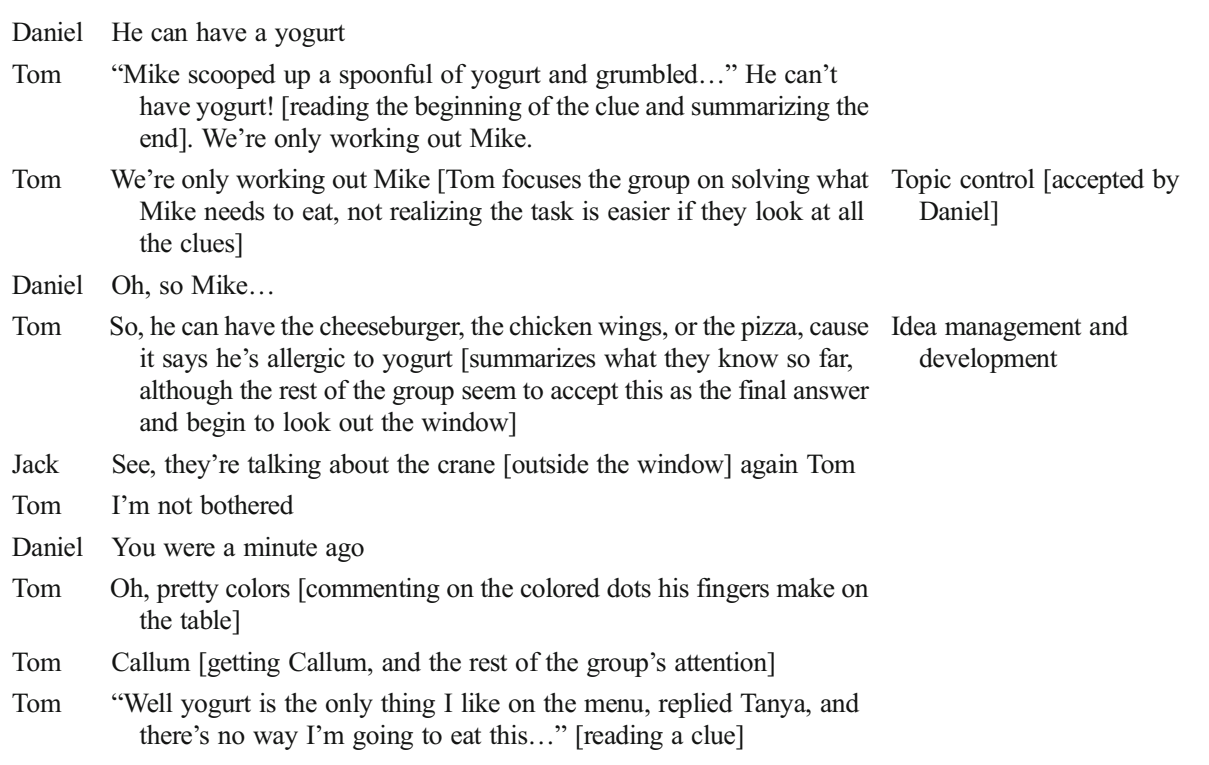

In the above vignette, Tom managed to maintain engagement on the topic, although his summary of what the group knows appears to be taken by them as the final answer. He returns to read a clue about yogurt aloud, which the group begins to attend to, but is interrupted by the teacher freezing the tables and discussion of the task with the whole class. During this whole-class discussion, the teacher helps the groups realize that they need to match each child to a food (e.g., Tanya gets the yogurt that Mike has, Grace gets the salad that Tanya has etc.). The groups return to working on the task, and Yadstone Green use the new strategy to try to find out what Mike should have. They manage to work through the clues, although they have not quite come to the final answer when the teacher calls the task to an end, and engages the whole class in a discussion about the answer.

The extracts from this group shows the fluidity of leadership between the tasks and the students. In the history task, Jack and Tom share leadership, although all students make organizational leadership bids that are accepted. Jack takes the lead in terms of the intellectual development of the task, while Tom is more concerned with organizing the activities. In contrast, in the math task, Tom emerges as a clear intellectual leader, while both he and Callum take on organizational roles.

\section{Discussion}

These two studies set out to examine emergent leadership in children's learning groups. Based on prior research, it was hypothesized that leadership would be distributed within the groups, as has been identified by Li et al. (2007) and Gressick and Derry (2010). Building on this, we examined if there were patterns within this distribution. In study one, findings indicated that the leadership moves were distributed among group members. The five leadership categories aligned with the concepts of intellectual and organizational leadership. However, leadership moves in general, and the two types of leadership specifically, did not appear to be consistent across task types. In study two, again, a distribution of leadership moves was identified, and the moves were classified into the two categories from study one: intellectual and 
organizational leadership. In the history task, seven groups have one student holding both these roles, while eight groups had two different leaders in these roles. A similar pattern as found in the math task, with nine groups showing one single leader and seven showing two students taking these different roles.

Taken together, studies one and two provide further support for the findings reported by Li et al. (2007) and Gressick and Derry (2010) that emergent leadership is distributed within groups, with more than one student making leadership moves that are accepted by the group members during the collaborative activities. Our analysis also builds on this earlier work to provide evidence for two leadership constructs - intellectual and organizational leadership. In both studies, we found as many cases of two people taking different leadership roles as cases of one person taking both roles. This indicates that while it is possible for the roles to be held by one person, they emerge as different roles, and should be considered as such. By looking across the two studies, it is possible to see that these different forms of leadership emerge in both an experimental situation, where just one group is working in the room with a teacher, and in a larger groups setting, more similar to a classroom environment, where the groups have to regulate their own actions without as much attention from the teacher.

By looking at the same groups across different content areas, our results provide further evidence for the distributed nature of emergent leadership, and also indicate that leadership does not emerge in the same way when groups are working on different tasks. Our findings also indicate that intellectual leadership moves, in particular Idea Management and Development, are most associated with task success, while organizational leadership seems to have a more complex relationship with task outcomes.

\section{Leadership across content areas}

Both studies found differences between the content areas - with more of both types of leadership in the math tasks in study one, and significantly more intellectual leadership moves in the math task than the history task in study two. These differences in leadership across content areas may be explained in a number of ways. One possibility is that the nature of the tasks influenced the emergent leadership. The history task was designed to foster divergent thinking, with no single correct answer, while the math tasks all had correct solutions. We may see more leadership in tasks with a clear answer, where members of the group feel more confident in directing the group, than they do when the group is meant to be discussing possible explanations for the problem. Additionally, the history task was a single activity, while the math task consisted of three different tasks, which may affect the need for leadership, and should be examined, in detail in further studies.

Another possible reason for the differences is the children's experiences with the content areas. Solving math problems is a common experience for the children in both studies, and they are aware of who is 'good at math' in their class. Historical thinking tasks are not as familiar to the students, nor is expertise in this domain as well recognized in the primary classroom. This may result in the children who are recognized as being good at math to take or be given the role of intellectual leader during the math task, while there was no such prior knowledge to base roles on during the history task, leading to less or more fluid leadership in the history task. Alternatively, the differences in the task types may be the cause of these differences, with students emerging as leaders differentially when the tasks are open-ended rather than closed tasks. Further research that separates task type from content area is necessary to understand this more completely. This finding reflects the findings by Yamaguchi (2001), who found differences in emergent leadership based on the task goals. These suggest that leadership will not emerge in every learning situation, but that it is dependent on the task that 
the group is engaged in. Further research is necessary to explore what types of tasks promote leadership, and where that leadership is necessary for task completion and learning.

In both studies, there was a change in leadership across the content areas, and in the second study, it was clear that the intellectual or organizational (or both) leaders changed. While management literature has argued for the stable nature of leadership (Kirkpatrick and Locke 1991), the changes that we see in our sample suggest that, at least for 10 year old children, emergent leadership in collaborative learning groups is not stable, even within the same group. Instead, leadership appears to be influenced by the content, echoing Yamaguchi's (2001) study that found task demands influenced the emergence of leadership. This suggests that the design of collaborative learning activities should take into account how the task may influence emergent leadership, and the impact that would have on the learning that will occur.

\section{Leadership and task outcomes}

Looking at outcome data in study two provides a complex picture of the relationship between leadership moves and group success. In the math tasks, there is a relationship between number of intellectual leadership moves and the groups' progress on the tasks, with increasing amounts of intellectual leadership being associated with increasing task success. When examined in detail, Idea Management and Development moves were most associated with positive outcomes, with all 12 groups who solved two or three of the tasks falling into the high category for this move. This suggests that this leadership move may be a key feature to solving constrained mathematical problems.

While organizational leadership and overall leadership were not significantly associated with task success, the relationship between turn management and success appears to be important. However the descriptive statistics in Table 8 suggest this should be interpreted with caution due to similarities in outcomes across the high and low categories. Fig. 8 and Table 8 both show high levels of organizational leadership in groups who were not successful, as well as in groups who were successful. This may indicate that organizational leadership is not sufficient for task completion, and that groups who are focused on the process, either because they were struggling to manage their interactions or because they were struggling with the content, were not making the type of progress necessary for solving the problems.

The history task was designed to be open-ended, focusing on the use of historical thinking skills and complex reasoning, rather than being a task with a single correct answer. The highest level of reasoning reached within the group is one way of assessing the outcomes of the groups, which again shows a complex pattern when plotted against the leadership moves. While results were not statistically significant, the descriptive patterns show most leadership moves were made in groups who reached the highest level of reasoning. The second highest level of moves, however, were in groups who did not get beyond the second level, only making comments about the relevance of the clues, but not combining them in any way. This may reflect the same type of issues seen in the math data, with groups struggling to work out how to participate in the task, and so needing more leadership moves, although they do not result in better outcomes. When the leadership moves are examined individually, the pattern remains. One concern that arises from this analysis, however, is that using the highest level of SOLO reasoning is not a sufficiently nuanced measure of success for this task. As SOLO was designed to assess open-ended written questions, it may not be the most precise measure of a group's progress. Further analysis, which is beyond the scope of this paper, could also use a temporal analysis approach, to provide a deeper understanding about the relationship between the leadership moves and the types of reasoning group members were engaged in. 
The case study

By examining the emergent leadership in the green group from Yadstone in study two, the complex nature of the groups' behavior can be seen as it changes across task type. While Tom and Callum appeared to make the most leadership moves, Callum made very few in the history task, and in both tasks, the majority of his moves were organizational. Tom made most of the intellectual leadership moves during the math task, but very few in the history task. Jack, not clearly a leader when the data is examined without being broken out by task or leadership type, made most of the intellectual leadership moves in the history task, helping the group to make sense of the clues in the history task, but participated as a follower for most of the math task. Thus, this group illustrates the importance of breaking down leadership both by task type, and by type of leadership, to fully understand the type of collaborative engagement seen in this group.

\section{Multi-touch technology}

Both studies used a new technology, multi-touch tables, to support the collaborative problem solving process. As prior research indicates that this type of technology can support collaboration, we examined differences between groups working on a paperbased version of the mystery tasks and a multi-touch version of the tasks in study one. As reported elsewhere (Higgins et al. 2012; Mercier et al. 2013) it was not possible to determine differences in success between conditions, as a teacher was present to support groups through the task. When comparing the number of leadership moves across conditions, however, we did not find any differences, suggesting that the technology did not influence the leadership part of the interactions in the same way it appears to have influenced how the students interacted around ideas. These results suggest that the findings about emergent leadership from study two, where all students worked on multitouch tables, could be generalized to other face-to-face collaborative interactions, regardless of whether technology is being used by the groups.

\section{Limitations and future research}

There are a number of limitations to the studies reported here, including the limited task types, the lab environment, the way the teachers engaged with the groups and the non-independence of the data, as is inherent in analysis of group interaction. The mystery tasks were designed to have a similar structure, and full engagement in the task by all group members was facilitated by members taking on the roles of organizational and intellectual leader. If students were engaging in a task that was less collaborative or less cognitively demanding, there may have been less need for the amount of leadership that was seen in these studies, and therefore less evidence for the distribution of leadership moves. Additionally, the first study used a very artificial environment, where each group worked with one teacher and where the data collection tools were evident to the groups. In the second study, although the lab classroom was designed to be as similar to a typical classroom as possible, data collection equipment was discrete and students were drawn from the same classroom, there are still differences between this and a typical classroom. The lab environment also meant that not all students who returned consent forms were selected to participate. While teachers were asked to select randomly, some suggested that they selected the better-behaved students, so we may have had fewer disruptions than would occur in a typical classroom with the full range of students. However, the use of the lab classroom does represent the use of new technologies and tools to examine 
collaborative learning across groups within the same classroom, allowing us to understand more about the actual nature of collaboration in a setting in which the teacher has to manage multiple groups. The decision to use the same two teachers across studies and schools meant that the level of teacher intervention was not the same as would be expected in a typical classroom environment where the teacher knows the students well, and although the teachers expressed a belief that their students' behavior didn't change, this cannot be ruled out, and further studies in traditional classrooms should be conducted to further explore our results. Finally, as with all analysis of group interaction, it should be noted that the individual data is non-independent, with the interactions of members of each group being dependent on those of the rest of their group. Thus the data does not meet the assumption of independence necessary for conducting parametric statistics, and as such, the analysis should be interpreted with caution.

As research on collaborative learning focuses more on the group process, and the mechanisms through which groups manage their participation, this study identifies key aspects of managing both the intellectual aspect of the problem space, and the organizational leadership that, while necessary to facilitate the development of a joint problem space, is also necessary to manage the interaction process. The organizational leader manages participation, while the intellectual leader manages the content, and while our data indicates this is done by a single group member in about half of the cases, in half of the groups the roles are held by different people.

As noted in the introduction, emergent leadership is one way in which the emergent management of group engagement has been studied. A parallel line of research considers how group members regulate their participation (Järvelä and Hadwin 2013). Building on ideas of social regulation, Volet et al. (2009) argue for a framework that takes into account both the social and content-based processing that are necessary for successful completion of collaborative work. This distinction echoes our findings, although the co-regulation definitions classify participation and engagement at an individual level, rather than examining the interaction behaviors that attempt to support or manage the interactions of other group members. Thus, we see the work in this area as complementary to the work on emergent leadership, describing how group members manage participation, by regulating their own participation, while the role of emergent leaders appears to be to manage the participation of other group members, and the direction of the content processing.

An increasing need to prepare students to engage in complex collaborations as they enter the workplace is frequently identified (e.g., OECD 2013) and research from management literature shows the importance of leadership in groups, particularly emergent leadership (Gronn 2002). Therefore, helping students to develop leadership moves and to identify the types of leadership that are necessary to complete tasks and recruit the participation of their group members, should go some way in helping prepare students for successful collaboration in the workplace. However, the philosophical roots of collaborative learning are often regarded to be at odds with leadership within groups. With the focus on using collaboration to alter the authority structures in schools, allowing students to view themselves as members of a knowledge community and building on theories that identify the importance of equitable status for learning (e.g., Cohen and Roper 1972), it can be difficult to align with the idea of leadership within groups. One important contribution of this paper, however, is that the emergent leadership described in this and other papers is not grounded in authority granted by the teacher. Also, although leadership may relate to classroom status, dynamics and prior relationships, the data in this paper indicates it is not stable across content areas, suggesting that it is not solely based on a single form of status. Li et al. (2007) also reported changes 
across time, with more leadership moves being identified in later activities, and more students being identified as leaders as the study progressed. As in both studies, students were peers from the same classrooms these findings indicate that emergent leadership may not be static, but can be learned (or perhaps taught) over time.

While there is currently little evidence that students can be taught leadership moves that transfer to new collaborative tasks, there is plenty of evidence to indicate that the use of scripts, prior instruction, or embedding of prompts or structure can lead to better collaborative interaction in groups. (e.g., Cortez et al. 2009; O'Donnell and Dansereau 1992; Rummel, Spada, and Hauser 2009). This prior work would indicate that students could be taught to take on the different leadership behaviors identified in this and earlier papers. Additionally, more recent research using the Collaborative Reasoning activity described by Li et al. (2007), suggests that leadership moves may be transferred to a new collaborative context (Sun et al. under review), suggesting that there is value to helping students develop these behaviors in one context as they can use them with different peers when working on different problems. Finally, the field of management, where much prior work on leadership exists, places emphasis on leadership training activities, suggesting that leadership can be taught, and there is value in exploring the instruction of leadership, and transfer of leadership moves, in future research work.

A large amount of work in collaborative learning focuses on and recommends the assignment of roles to student groups (O'Donnell 2006), One particular reason for assigning roles is the recognition that equitable participation does not have to mean all students engage in the same behaviors throughout the task, and that valuing the differences across members of a group can support increased equity (Cohen 1994). It should be noted, however, that while leaders are frequently one type of assigned roles, earlier research and the research in this paper shows that leadership moves may be distributed among group members, and there is the potential for different forms of leadership to emerge. Thus, the assignment of the role 'leader' may not provide sufficient instruction for students on what type of leadership moves they should be making and should perhaps be broken down into more specific roles both in assigning roles and also in helping students understand the complexity of collaborative engagement. However, as is seen in the vignette at the beginning of this paper, attention should be paid to the level of engagement with the content for those involved in organizational leadership, as such behavior might fulfill the goal of being involved in the activity, without providing a good learning opportunity for the student. In addition, our findings indicate that high levels of organizational leadership might not be associated with positive group outcomes, and so teachers need to be alert to the types of content-related conversation that occur in groups who appear to have high levels of organizational leadership, intervening to ensure that both the organizational and intellectual aspects of the task are attended to by all members of the group. Preparing students to engage in collaborative activities should help them consider the dual space nature of collaboration - the relational and problem spaces so that they are aware that leadership must take place in both realms, but that task success, and potentially their learning, will depend on intellectual leadership and engagement.

Acknowledgments The research described in this paper was funded through the UK's Teaching and Learning Research Programme (TLRP) Technology Enhanced Learning (TEL) Phase 5, funded jointly by the ESRC and EPSRC, grant number RES-139-25-0400. Any opinions, findings and conclusions expressed in the paper are those of the authors and do not necessarily reflect the views of the sponsoring agencies. The authors wish to acknowledge the schools and students who participated in this study. The authors also acknowledge the contribution of the SynergyNet project team in the development of work presented here. 


\section{Appendix: Tasks}

Math Mysteries

Sneaky Sydney.

Question: In which room is the statue hidden?

Clues:

- Sneaky Sydney has stolen a special stone statue.

- The room number the statue is in is not less than 25 .

- The room number where the statue is hidden is not even.

- He has hidden it in a bedroom in the Grand Hotel.

- The Grand Hotel is next to the station.

- The room number where Sydney has hidden the statue is not 25.

- The Grand Hotel is not as expensive as the Caesar Hotel across the street.

- The room number does not contain the digit 3.

- There are 100 rooms in the Grand Hotel.

- The room number where it is hidden is a multiple of 5 .

- The statue is in a room whose number is lower than 50 .

- The statue is small, heavy and very valuable.

Waltzer.

Question: How much will it cost the Waltzer owner for enough cuddly monkeys for a day?

Clues:

- At the fair there is a Waltzer

- To get people to go on it the owner offers a prize

- Every 10th person to go on will be given a cuddly toy monkey

- It costs the owner $£ 2$ to buy one monkey

- The monkeys look happy

- 3 people can sit together in a car

- There are 15 cars altogether on the Waltzer

- You must be at least 10 years old to ride the Waltzer

- There are 10 rides every hour

- The fair is open for $8 \mathrm{~h}$ a day

- All the spaces are taken for every ride all day

- How much will it cost for the owner to buy one monkey for every 10th person who goes on the Waltzer?

Dinner Disaster.

Question: Can you work out what Mike should have to eat?

Clues:

- The new cook at school, Mrs Baker, has mixed up the trays with the children's school dinners on.

- "YUCK!" cried Ruby, making a face at the slice of pizza in front of her. "I can't stand pepperoni!"'”

- "Don't look at me," moaned Jack. "I hate any food with cheese on it." At that, he pushed away his cheeseburger. 
- "Hey, anybody want these chicken wings?" asked Grace. "I don't like anything with meat in it."

- Mike scooped up a spoonful of his yogurt and grumbled, "Everybody knows I'm allergic to this stuff."

- "Well, yogurt is the only thing I like on the menu," replied Tanya. "And there's no way I'm going to eat THIS!" At that, she poked her salad with a fork.

\section{History Mystery}

Question: What happened to Robert Dixon? Whose fault was it?

Introduction (Read aloud to students):

Richardson Mining Company, Carnington Pit: Accident Report

Report on the unfortunate accident to Robert Dixon, aged ten of 15, Clyde Street, Carnington. The accident occurred at approximately $4 \mathrm{pm}$ on Wednesday 23rd August. The miners working in a nearby tunnel rushed to the scene hearing the boys cries. It appears that the boy's leg was run over by a 500cwt coal truck in No. 3 underground railway. The leg was completely crushed and had to be amputated on the spot. No witnesses saw the accident because there was no light in that part of the mine, but it seems likely that the boy had fallen asleep with his leg over the rail. The incident would seem to have been an unfortunate accident. No blame could be apportioned to any employee of the Richardson Mining Company.

Signed John Robson

\section{Clues:}

- Mrs. Richardson, the mine owner's wife, wants an expensive house in the country because she says that it is too dirty living near the mine.

- The coalmine is the only employment in the village.

- The mine supervisor, John Robson, was feeling ill that morning as a result of too much ale the night before and did not check the wheels on the carts like he sometimes did.

- The mine inspectors had reported that there was not enough fresh air in the mine, but John Robson thought they were being too fussy and had not done anything about it.

- At this time it was not against the law for 10 year-old boys to work underground.

- Workers in the mine had to supply their own candles.

- Wages varied depending on the price of coal. If the price was low the miners had to dig more coal to keep the same wage and worked longer hours.

- Robert Dixon is 10 years old. He works underground as a trapper. He opens the doors to let the coal trucks through. He has been working at the mine for two years.

- Last year Robert's dad, William Dixon, died in an explosion at the pit. 53 men and boys were killed. A fund was set up for their families. Sir Charles Richardson, the mine owner, gave some money, but there was not much for each family.

- Robert usually works from 6 am to $6 \mathrm{pm}$, but has recently had to work longer because his wages had gone down.

- The weather has been unusually hot this summer.

- Robert gets up at $5 \mathrm{am}$. He has bread and tea for breakfast and then walks to the pit. He has a break at 11 am for bread and tea. When he gets home he has some more bread and cheese or meat, if the family can afford it, then goes to bed.

- Ropes operated by a steam engine pull the coal trucks down the mine. Only one person is needed to pull a whole line of trucks. Until recently horses pulled the trucks.

- Robert's mother, Anna Dixon, has been very ill after the birth of her ninth child. She has to stay in bed.

- Robert has six younger brothers and sisters. His older sister, Mary, works as a scullery maid for Sir Charles. His older brother William is a miner at the same pit as Robert. 
Open Access This article is distributed under the terms of the Creative Commons Attribution License which permits any use, distribution, and reproduction in any medium, provided the original author(s) and the source are credited.

\section{References}

Avolio, B. J., Walumbwa, F. O., \& Weber, T. J. (2009). Leadership: current theories, research, and future directions. Annual review of psychology, 60, 421-49. doi:10.1146/annurev.psych.60.110707.163621.

Basheri, M., Burd, L., Munro, M., \& Baghaei, N. (2013). Collaborative Learning Skills in Multi-touch Tables for UML Software Design. International Journal of Advanced Computer Science and Applications, 4(3), 60-66.

Bass, B. M., \& Bass, R. (2009). The Bass handbook of leadership: Theory, research, and managerial applications. SimonandSchuster.com.

Barron, B. (2003). When Smart Groups Fail. Journal of the Learning Sciences, 12(3), 307-359. doi:10.1207/ S15327809JLS1203 1.

Barron, B., Martin, C.K., Mercier, E.M., Pea, R., Steinbock, D., Walter, S., Herrenkohl, L. Mertl, V., Tyson, K., (2009). Repertoires of Collaborative Practices. In C. O’Malley, D. Suthers, P. Reimann \& A. Dimitracopoulou (Eds.) Computer-Supported Collaborative Learning Practices: CSCL2009 Conference Proceedings. Volume II. International Society of the Learning Sciences, 25-27.

Bennett, N., Harvey, J. A., Wise, C., \& Woods, P. A. (2003). Desk study review of distributed leadership. Nottingham: National College for School Leadership.

Biggs, J. B., \& Collis, K. F. (1982). Evaluating the quality of learning-the SOLO taxonomy (1st ed.). New York: Academic Press.

Bowers, D. G., \& Seashore, S. E. (1966). Predicting organizational effectiveness with a four-factor theory of leadership. Administrative Science Quarterly, 11, 238-263.

Cohen, E. G. (1994). Restructuring the classroom: Conditions for productive small groups. Review of Educational Research, 64(1), 1-35. doi:10.3102/00346543064001001.

Cohen, E. G., \& Roper, S. S. (1972). Modification of Interracial Interaction Disability: An Application of Status Characteristic Theory. American Sociological Review, 37(6), 643-657.

Cortez, C., Nussbaum, M., Woywood, G., \& Aravena, R. (2009). Learning to collaborate by collaborating: A face-to-face collaborative activity for measuring and learning basics about teamwork. Journal of Computer Assisted Learning, 25(2), 126-142. doi:10.1111/j.1365-2729.2008.00298.x.

Department for Education and Employment (DfEE) (1999). The National Numeracy Strategy London: DfEE.

Dillenbourg, P., \& Evans, M. (2011). Interactive tabletops in education. International Journal of ComputerSupported Collaborative Learning, 6(4), 491-514. doi:10.1007/s11412-011-9127-7.

Edwards, C. A. (1994). Leadership in groups of school-age girls. Developmental Psychology, 30(6), 920-927. doi:10.1037/0012-1649.30.6.920.

French, D. C., \& Stright, A. L. (1991). Emergent Leadership in Children's Small Groups. Small Group Research, 22(2), 187-199. doi:10.1177/1046496491222003.

Gibb, C. A. (1954). Leadership. In G. Lindzey (Ed.), Handbook of social psychology (Vol. 2, pp. 877-917). Reading: Addison-Wesley.

Gressick, J., \& Derry, S. J. (2010). Distributed leadership in online groups. International Journal of ComputerSupported Collaborative Learning, 5(2), 211-236. doi:10.1007/s11412-010-9086-4.

Gronn, P. (2002). Distributed leadership as a unit of analysis. Leadership Quarterly, 13, 423-451.

Hackman, J. R. (Ed.). (1990). Groups that work (and those that don't): Creating conditions for effective teamwork. Jossey-Bass.

Harris, A., Rick, J., Bonnett, V., Yuill, N., Fleck, R., Marshall, P., \& Rogers, Y. (2009). Around the table: are multiple-touch surfaces better than single-touch for children's collaborative interactions? Proceedings of the 9th international conference on Computer supported collaborative learning-Volume 1 (pp. 335-344). International Society of the Learning Sciences.

Higgins, S., Mercier, E., Burd, L., \& Joyce-Gibbons, A. (2012). Multi-touch tables and collaborative learning. British Journal of Educational Technology, 43(6), 1041-1054. doi:10.1111/j.1467-8535.2011.01259.x.

Higgins, S. E., Mercier, E. M., Burd, E., \& Hatch, A. (2011). Multi-touch tables and the relationship with collaborative classroom pedagogies: a synthetic review. International Journal of Computer-Supported Collaborative Learning., 6(4), 515-538. doi:10.1007/s11412-011-9131-y.

Järvelä, S., \& Hadwin, A. F. (2013). New Frontiers: Regulating Learning in CSCL. Educational Psychologist, 41(1), 25-39. doi:10.1080/00461520.2012.748006.

Johnson, D. W., \& Johnson, R. T. (2009). An Educational Psychology Success Story: Social Interdependence Theory and Cooperative Learning. Educational Researcher, 38(5), 365-379. doi:10.3102/ 0013189X09339057. 
Kharrufa, A., Balaam, M., Heslop, P., Leat, D., Paul Dolan, Olivier, P. (2013) Tables in the Wild: Lessons learned from a large-scale multi-tabletop deployment. Proceedings of the ACM SIGCHI Conference on Human Factors in Computing Systems 2013. CHI'13.

Kirkpatrick, S., \& Locke, E. (1991). Leadership : do traits matter? The Executive, 5(2), 48-60.

Leat, D., \& Higgins, S. (2002). The role of powerful pedagogical strategies in curriculum development. The Curriculum Journal, 13(1), 71-85. doi:10.1080/09585170110115286.

Li, Y., Anderson, R., Nguyen-Jahiel, K., Dong, T., Archodidou, A., Kim, I. H., et al. (2007). Emergent leadership in children's discussion groups. Cognition and Instruction, 25(1), 1-2. doi:10.1080/07370000709336703.

Martinez-Maldonado, R., Kay, J., Yacef, K., Edbauer, M.-T., \& Dimitriadis, Y. (2013). MTClassroom and MTDashboard: supporting analysis of teacher attention in an orchestrated multi-tabletop classroom. Proceedings of the International Conference On Computer-Supported Collaborative Learning, 1, 320-327.

Mercier, E. M., \& Higgins, S. (2013). Collaborative learning with multi-touch technology: developing adaptive expertise. Learning and Instruction, 25, 13-23. doi:10.1016/j.learninstruc.2012.10.004.

Mercier, E., Higgins, S., Burd, E. \& Joyce-Gibbons, A. (2012). Multi-Touch Technology to Support Multiple Levels of Collaborative Learning in the Classroom. In van Aalst, J., Thompson, K., Jacobson, M. J., \& Reimann, P. (Eds.) The Future of Learning: Proceedings of the 10th International Conference of the Learning Sciences (ICLS 2012) - Volume 2.

Mercier, E., Vourloumi, G., \& Higgins, S. (2013) Idea development in multi-touch and paper-based collaborative problem solving. In N. Rummel, M. Kapur, M. Nathan, \& S, Puntambekar, S. (Eds.) To See the World and a Grain of Sand: Learning across Levels of Space, Time, and Scale: CSCL 2013 Conference Proceedings Vol 2, 313-4.

Miller, B., Sun, J., Wu, X., Anderson, R.C. (2013). Child Leaders in Collaborative Groups. In C.E. Hmelo-Silver, C.A. Chinn, C.K.K. Chan \& A. O'Donnell (Eds) The International Handbook of Collaborative Learning. Routledge.

Mumford, M., Zaccaro, S., Harding, F., Jacobs, T., \& Fleishman, E. (2000). Leadership skills for a changing world: solving complex social problems. Leadership Quarterly, 11(1), 11-35. doi:10.1016/S1048-9843(99)00041-7.

National Council of Teachers of Mathematics. (2000). Principles and standards for school mathematics. Reston: NCTM.

O’Donnell, A. (2006). The role of peers and group learning. In P. Alexander \& P. Winne (Eds.), The Handbook of Educational Psychology (2nd ed., pp. 781-802). Lawrence Earlbaum.

O’Donnell, A. M., \& Dansereau, D. F. (1992). Scripted cooperation in student dyads: A method for analyzing and enhancing academic learning and performance. In Interaction in cooperative groups: The theoretical anatomy of group learning (pp. 120-141). Cambridge: Cambridge University Press.

OECD (2013) PISA 2015 Draft Collaborative Problem Solving Framework. Downloaded from http://atc21s.org/ index.php/oecd-conceptual-framework-for-2015-pisa-assessment-of-problem-solving/.

Pearce, C. L., \& Conger, J. A. (2003). Shared leadership - reframing the hows and whys of leadership. Thousand Oaks: Sage.

Roschelle, J. (1992). Learning by collaborating: Convergent conceptual change. The Journal of the Learning Sciences, 2(3), 235-276.

Rummel, N., Spada, H., \& Hauser, S. (2009). Learning to collaborate while being scripted or by observing a model. Journal of Computer-Supported Collaborative Learning, 69-92. doi:10.1007/s11412-008-9054-4.

Schellens, T., Van Kerr, H., De Wever, B., \& Valcke, M. (2007). Scripting by assigning roles: Does it improve knowledge construction in asynchronous discussion groups? International Journal of Comptuer-Supported Collaborative Learning, 2, 225-246. doi:10.1007/s11412-007-9016-2.

Seiler, S., \& Pfister, A. (2009). "Why did I do this?”: Understanding leadership behavior through a dynamic fivefactor model of leadership. Journal of Leadership Studies, 3(3), 41-52. doi:10.1002/j1s.

Spillane, J. P. (2005). Distributed leadership. The Educational Forum, 69, 143-150. doi:10.1080/ 00131720508984678 .

Stahl, G. (2006). Group cognition: Computer support for building collaborative knowledge. Cambridge: MIT Press.

Sun, J., Anderson, R.C., Perry, M. \& Lin, T-J. (under review) Transfer of Emergent Leadership from Collaborative Reasoning to Cooperative Problem Solving.

Suthers, D. D. (2006). A qualitative analysis of collaborative knowledge construction through shared representations. Research and Practice in Technology Enhanced Learning (RPTEL), 1(2), 1-28.

Suthers, D. D., Dwyer, N., Medina, R., \& Vatrapu, R. (2010). A framework for conceptualizing, representing, and analyzing distributed interaction. International Journal of Computer-Supported Collaborative Learning, 5(1), 5-42.

Volet, S., Summers, M., \& Thurman, J. (2009). High-level co-regulation in collaborative learning: How does it emerge and how is it sustained. Learning and Instruction, 19, 128-143. doi:10.1016/j.learninstruc.2008.03.001.

Weinberger, A., Ertl, B., Fischer, F., \& Mandl, H. (2005). Epistemic and social scripts in computer-supported collaborative learning. Instructional Science, 33, 1-30. doi:10.1007/s11251-004-2322-4.

Yamaguchi, R. (2001). Children s learning groups: a study of emergent leadership, dominance, and group effectiveness. Small Group Research, 32(6), 671-697. doi:10.1177/104649640103200601.

Yamaguchi, R., \& Maehr, M. L. (2004). Children's emergent leadership: the relationships with group characteristics and outcomes. Small Group Research, 35(4), 388-406. doi:10.1177/104649640426327. 